\title{
Impact of Advancement of Technology, Competitive Pressure, User Expectation on Continuous Digital Disruption: Mediating Role of Perceive Ease of Use
}

\author{
Sylvia Addison \\ International University of Malaya-Wales, Kuala Lumpur, Malaysia \\ Email: saddison1980@gmail.com
}

How to cite this paper: Addison, S. (2021). Impact of Advancement of Technology, Competitive Pressure, User Expectation on Continuous Digital Disruption: Mediating Role of Perceive Ease of Use. Open Journal of Business and Management, 9, 2013-2079. https://doi.org/10.4236/ojbm.2021.94109

Received: January 7, 2021

Accepted: July 27, 2021

Published: July 30, 2021

Copyright (อ 2021 by author(s) and Scientific Research Publishing Inc. This work is licensed under the Creative Commons Attribution International License (CC BY 4.0).

http://creativecommons.org/licenses/by/4.0/

(c) (i) Open Access

\begin{abstract}
The purpose of this research was to determine the impact of advancement of technology, competitive pressure, and user expectation on continues digital disruption using perceive ease of use role as a mediator. This study proposed a conceptual framework to investigating the significant factors of the various variables through critical evaluation of associated theoretical models, literature studies, and empirical tests. The proposed conceptual framework examined 292 final samples from targeted populations aged 18 years or older, working with digital technologies in Kuala Lumpur, Malaysia, using a positivism research philosophy and explanatory research design. The Survey questionnaires collected were extensively tested for reliability and validity. Empirical data were analyzed using "Exploratory Factor Analysis" (EFA), "Confirmatory Factor Analysis" (CFA), and "Structural Equation Modeling" (SEM) via AMOS 22 software. Research findings indicate that advancement of technology has an insignificant negative impact on continuous digital disruption. User expectation has a positive, negligible effect on digital disruption. However, competitive pressure showed a negative impact on continuous digital disruption. The role of perceived ease of use as a mediator on continuous digital disruption indicated a positively negligible impact. Perceived ease of use role as a mediator on competitive pressure and user expectations showed a positive marginal effect. Lastly, perceived ease of use as a mediator for advancement of technology was negatively insignificant. In conclusion, all the hypotheses proposed were rejected based on these findings, except for hypothesis (H2). The main contribution of this paper was to determine the actual factors contributing to the unceasing digital disruption in organizations and institutions and also identify the correlation between advancement of tech-
\end{abstract}


nology, user expectations, and competitive pressure on continuous digital disruption, using perceive ease of use role as a mediator.

\section{Keywords}

Advancement of Technology, Competitive Pressure, User Expectation, Continuous Digital Disruption, Digitalization, Digital Technologies, Perceive Ease of Use

\section{Introduction}

This research aims to determine the impact of advancement of technology, competitive pressure, user expectation on continuous digital disruption using perceive ease of use role as a mediator in Kuala Lumpur Malaysia. According to Gartner Glossary (2020), digital disruption is described as an impact that transforms the basic perceptions and behaviours of culture, market, industry, or process using digital capabilities, channels, or assets. Rauch et al. (2016), mentioned that continuous digital disruption is driven by the advent of the latest innovation, such as developments in automation, robotics, business intelligence, cloud computing, and new software that makes it easier for industrial systems to integrate all these technologies and more. Westerman and Bonnet (2015), stated that digital disruption could shake the heart of all industries and trigger "short fuse, big bang" scenarios that could destroy the entire industry. Stewart et al. (2016), concluded that it's important for organizations to achieve a crucial knowledge of digital disruption to guarantee the sustainability of their operations as due to continuing digital disruption, many industries have been brought to their knees. The researcher also cited the decline of newspapers as a notorious example, similarly, the hotel industry is another example, as it has been forced by ventures like Airbnb and GuestHouser.com, to adapt to this new competition and the same is true of the taxi industry. As a result, continuous digital disruption is expected to impact every organization, business strategy, and decision-making sector (Rossi, 2017).

According to Perdana (2019), Malaysian companies are still lagging in the adoption of digital technologies due to the perception that they appear to be fast-paced and complex. Budget limitations and the lack of digital professionals in the country are critical factors. TheStar (2019) also mentioned that non-digital companies in Malaysia are waking up to the dangers they face in the hands of digital disruptors, and many are now in the initial stages of reinventing digital tools. This poses a significant opportunity for businesses outside Malaysia who are hoping to enter the competitive market (Shim, 2019).

\subsection{Research Background}

Digital disruption has gained lots of global attention in recent years, especially in 
academia (Gartner Glossary, 2016; Elbanna \& Newman 2016; Legner et al., 2017; Gimpel et al. 2018; Parida, Sjödin \& Reim, 2019). According to Von Briel et al. (2018), one of the benefits of continuous digital disruption is its expedition and facilitation of the business start-up process. According to Research, Christensen used digital disruption for the first time (Christensen, 1997). However, several researchers in the digitalization sector, Artificial intelligence, virtualization, Big Data, etc. have investigated determining factors of continuous digital disruption, and the results are inconsistent and inconclusive. Also, most previous studies on digital disruption or disruptive technologies focused on developed countries with well-developed Information Communication Technologies and on a different aspect of digital disruption rather than the impact of technological advancement, competitive pressure, user expectation on continuous digital disruption, and using perceived ease of use as a mediator in developing countries (Legner et al., 2017; Fossen \& Sorgner, 2018; Parida, Sjödin, \& Reim, 2019).

Furthermore, Teo et al. (2018) researched digital disruption in the Malaysian transportation sector using Grab as a case study. The researcher found that Grab car ride-sharing is shifting commuters and drivers from conventional taxi services to their network through digital technology.

\subsection{Research Rationale}

Research has shown that it is expected that fifty billion smart devices will be connected to the Internet (IoT) and to have a $\$ 7$ trillion economic impact by 2020 (Wortmann \& Flüchter, 2015). Parida, Sjödin and Reim (2019), define digitalization as a revolutionary way of doing business through the use of augmented reality (IoT), innovations, intensive data exchange, and statistical analysis. Digitalization is described as the use of digital technology in industry and society, and its associated changes in the connectivity of individuals, organizations, and objects (Gartner Glossary, 2016; Gimpel et al., 2018). According to Parida, Sjödin, \& Reim (2019), digital innovations such as digital platforms, artificial intelligence, virtualization, cloud computing, robotics, and business intelligence can be used as an innovative business paradigm to improve efficiency of companies. Legner et al. (2017), define digitization as a process for the acceptance and use of digital technologies in a wider individual, institutional, and socio-cultural context. Gimpel et al. (2018), alleged that digital technology alters the structures of the industry, empowers customers, and affects our privacy. Tan et al. (2016), reported that, besides the obvious benefits of digitalization, it also disrupts the orthodox way of doing business. The scholar also mentioned that digital disruption has become prevalent as a result of the proliferation of technologies.

Li et al. (2017) referred to digital disruption as any new or enhanced technology that substitutes or disrupts prevailing technologies, making it obsolete. Li et al. (2017) further mentioned that digital disruption dramatically alters the way companies or entire industries work. Greenwood \& Wattal (2017) mentioned 
that digitalization and its modern form of business activity can interrupt and place prevailing businesses, goods, or services at substantial risk. Hence, this present study focuses on the effect of advancement of technology, competitive pressure, user expectations, and perceived ease of use role as a mediator on continued digital disruption in Kuala Lumpur Malaysia.

\subsection{Significance of the Study}

This thesis will offer many benefits to Malaysian businesses, companies, organizations, academics, and future researchers.

The research will provide information to academia, future researchers, entrepreneurs, and business owners in Malaysia, in understanding the factors contributing to the unceasing digital disruption. It will also enable them to make informed decisions on the appropriate digitalization technology they should adopt in this era of digital disruption. The thesis will act as research material for future research on the determinants of digital disruption in Malaysia. Finally, this research will add to the existing knowledge of the factors affecting continual digital disruption in academia.

\subsection{Aims of the Study}

The goal of the research was to explore the impacts of advancement of technology, competitive pressure, user expectation, on continuous digital disruption, using perceive ease of use role as a mediator in Kuala Lumpur Malaysia.

\subsection{Objectives of the Study}

The thesis aimed to achieve the following research objectives:

RO1: To determine the impact of Advancement of technology on continuous digital disruption in Kuala Lumpur Malaysia

RO2: To determine the impact of Competitive pressure on continuous digital disruption in Kuala Lumpur Malaysia

RO3: To determine the impact of User expectation on continuous digital disruption in Kuala Lumpur Malaysia

RO4: To determine the impact of Advancement of technology on Perceived ease of use in Kuala Lumpur Malaysia

RO5: To determine the impact of Competitive pressure on Perceived ease of use in Kuala Lumpur Malaysia

RO6: To determine the impact of User expectation on Perceived ease of use in Kuala Lumpur Malaysia

RO7: To determine the impact of Perceived ease of use as a mediator on the relationship between Advancement of technology, Competition pressure, User expectation, and Continuous digital disruption in Kuala Lumpur Malaysia.

\subsection{Research Questions}

The following research questions were asked to attain the research goals. 
RQ1: What is the impact of Advancement of technology on Continuous digital disruption?

RQ2: What is the impact of Competitive pressure on Continuous digital disruption?

RQ3: What is the impact of User expectation on Continuous digital disruption?

RQ4: What is the impact of the Advancement of technology on Perceived ease of use?

RQ5: What is the impact of Competitive pressure on Perceived ease of use?

RQ6: What is the impact of User expectation on Perceived ease of use?

RQ7: What is the impact of Perceived ease of use as a mediator on the relationship between the Advancement of technology, Competition pressure, User expectation, and Continuous digital disruption?

\section{Literature Review}

\subsection{Review of Key Concepts}

\subsubsection{Advancement of Technology}

According to Reddy and Zhao (1990), advancement of technology has many concepts from earlier literature (Wahab et al., 2012). Valverde (2016) first described technological advancement as the application of structured information to practical tasks through ordered human and computer systems (Valverde, 2016). In three conflicting views, Mokyr examined technological advancement as a liberator, a threat, and an instrument of power (Barbour, 2014). Mesthene (1970), of Harvard University, defined technological advancement as a neutral tool. To the researcher, it is up to the user to decipher their use which does not guarantee any particular consequences. However, Vogels et al. (2020) reported that technological advancement seems difficult to define and understand. Bain (1937) added that Christianity encourages people to see technological advancement as a tool given by God to transform the earth into a new Garden of Eden. According to Unctad (2018), Technology advancement is now an indispensable part of human existence and has a profound influence on all economy, society, research, arts, and daily life. The scholar further noted that to participate effectively in project designs and technology policy the public needs technological literacy.

Arthur (2009), a pioneering thinker and economist in technology advancement, asserted that technological advancement creates our world more than anything else. Similarly, Schwab (2016) stated that the concept of technology advancement has shifted from the industrial (industrial revolution) to the information age. He asserts that businesses with large economic muscles tend to use expensive technological tools during the industrial period to gain a competitive edge over small businesses but of late advancement of technology has created a new paradigm shift known as the information age that provides a different framework for the highly competitive market. Harding et al. (2015) confirmed that 
these innovations are accelerating us towards a new industrial revolution. Andreas Schleicher of the Organization for Economic Cooperation and Development (OECD) claimed in an international survey that technology is doing more harm than good in our schools today. According to the conclusions of the global report, students who used technologies at school regularly have slightly lower learning results than students who used technology only occasionally. However, students who used computers very often at school fared a lot worse, even when accounting for the student's socioeconomic status. According to the author, as a result, countries that have invested heavily in educational technology have seen no improvement in literacy, arithmetic, or scientific achievement. Madary and Metzinger (2016) alleged that the presence of technological advancement deprived this generation of far more than they can imagine because we have not taken the initiative to use technology as a weapon rather than a slave. Karki et al. (2018) stated that people who use technology regularly develop health issues such as back pain, headaches, and eye problems. It can also contribute to obesity due to a lack of physical activity. Holzer (2018) also mentioned that technological advancement is destroying workers and turning humans into robots. He alleged that technological innovation is causing us to lose all of our thinking and that there will soon be no such thing as independent thought. Tenner (2019) investigates the human-technology interaction. He contends that humans and technology have a give-and-take partnership that enables technology and humans to develop continuously. According to the study, technology occurs when humans have a desire or need for it. Tenner concludes that the physical impact of technological advancement on society is not good nor bad. McArthur and Sachs (2002) reported that, since the advancement of technology is at a threshold, Asian economies now require a new approach to technological growth. In this research, advancement of technology was defined as the generation of information or the discovery of knowledge or new technologies that create and improve easier ways of living comfortably and prolong lives for humankind.

\subsubsection{Competitive Pressure}

Competition pressure is the level of competition in the business sector (Soewarno et al., 2020). According to Bernard et al. (2006), competitive pressure arises when companies compete with competitors on the commodities market through frequent competitive interactions with other firms seeking to win customers, raise market shares, or struggle for survival. Porter (1995) defined competitive pressure as the extent to which companies exert pressure on one another. Porter (1998) reported that, by using five strength models that influence industrial competition, an organization's survival effort under competitive pressure within an industry increase (Bruijl, 2018). These strengths to the scholar are the new entrants, the substitutes, the ability to negotiate with manufacturers, the ability to attract consumers, and the ability to compete with competitors in the market. Porter further stated that rivalry pushes teams and individuals to do their best, 
be it in industry or other environments. Reich and Benbasat (1990) specified that competitive pressures arise when an organization allocates resources to offer innovative products or services in a highly competitive environment to respond to competitors. Menon et al. (1999) stated that management's inability to evaluate recent trends in the competitive landscape contributes to sales loss.

Additionally, Soewarno et al. (2020) reported that when there is a high degree of consumer demand, companies are more likely to pursue creativity, than when there is a low level of competition, resulting in higher transformative adoption. Turner and Endres (2017) advised that entrepreneurs must continue their survival efforts in the face of environmental change and competitive pressure because competition pushes entrepreneurs to think more creatively to outperform their rivals, resulting in revolutionary creativity. The researchers testified that competitive pressure drives companies to think more creatively about achieving something different from their competitors, thereby encouraging disruptive innovation. Furthermore, Frésard and Valta (2012) argued that competitive pressure forces management to focus on competitive threats and maximize value creation. Toolan (2017) established that high-tech organizations are fiercely responding to R\&D competition, while low-tech organizations are only following the market. Yang (2010) reported that consumer preference influences competitive market demand on companies, and it may impact $\mathrm{R}$ and $\mathrm{D}$ incentives to perform innovation competence. Tzini and Jain (2018) revealed that when competitive pressure is high, people are more likely to behave unethically than when competitive pressure is low. Leonidou et al. (2015) alleged that product innovation is an easy way to outperform competition. Dahlman (2018) concluded that the easing of trade barriers facilitates the penetration of foreign rivals into local markets, which increases the competitive pressure on firms. In this research, competitive pressure was described as the level of pressure companies experienced by industrial competitors due to their adaptation to new digital technologies.

\subsubsection{User Expectation}

Genesys (2020) described user expectations as aligning the company products and services to what customers want and need to optimize growth and productivity. Spreng and Thomas (2001) defined user expectations as customer perceptions of future product features or outcomes. Kujala et al. (2017) detailed that customer expectations dictate what consumers expect from a service or product. According to Greif and Garfinkel (2016), the changing force that companies must address to create more efficient and lower-cost products is user expectation. However, to Koenig-Lewis and Palmer (2014), user expectations can be linked to how or what a person may expect when using a service. Sun and Scanlon (2019) revealed that, in an era where new technologies: Cloud computing, Big Data, and Machine Intelligence are being democratised or made available to enterprises of all sizes, customer expectations are the primary difference. So, it is no surprise that top-performing brands like Amazon, Google, Ford, Apple, and 
others all deliver outstanding customer experiences.

Additionally, Meena \& Ganesan (2019), for companies to remain competitive, they must adapt to satisfy market demands. According to the researcher, businesses across all industries must keep up with growing economies, new trends, and evolving customer needs. Redbord (2020) indicated that technological innovations are causing a change in how companies treat customer service, allowing customers to react with even higher expectations. Vanhaverbeke (2017), research on innovation showed how businesses benefit from customers and users in the innovation process. He also stated that acquiring established users' expertise early in the innovation process enables companies to understand their interests and steer development in the right direction. Schwab (2016) contended that in this period of exponentially revolutionary technological change, known as the Fourth Industrial Revolution, cutting-edge products and services become outdated the next day. In this regard, a company's ability to differentiate itself is becoming exceedingly important. Van Belleghem (2015) mentioned that speed is one reason for user expectation because the external clock ticks faster than the internal clock. Meaning, customers can switch overnight if they wish. The scholar further stated that customers are disrupting because companies are slower than the market. Salesforce Research (2020) concluded that customers have high expectations of firms but don't trust them to deliver because consumers believe most companies fall short of their aspirations for better experiences. In this research, user expectation was what users or customers expect companies to offer in product or service quality based on the latest trends.

\subsubsection{Continuous Digital Disruption}

Continuous digital disruption is characterized as a continuous change brought about by emerging digital technologies and business models that could add value to existing products and services provided (Rachinger et al., 2019). Generally, from the viewpoint of businesses that have invested extensively in old systems, digital innovation is seen as disruptive. Digital disruption, according to research, may have a disruptive effect on market innovations or technology innovations. According to Karimi and Walter (2015), scholars have identified product and service digitization as a highly disruptive process. The scholars mentioned that this has resulted in significant disruption to existing companies' and incumbents' competencies. According to Elbanna and Newman (2016), as businesses face the risk of digital disruption because of the ferocity and structural vastness of the environmental shift, there is an urgent need for them to respond to the declining market outcomes. Christensen's (1997) study similarly demonstrated that incumbent corporations' business models support their current clients to such a degree that transitioning to more disruptive structures is challenging. Christensen and Raynor (2003) indicated that as a result of digital disruption, incumbent businesses are motivated to find new competitive market segments in which they position their core product or service and thereby transfer their industry to new 
market segments. The researcher reported that the advent of digitization causes a demand change in well-structured businesses. Farmer et al. (2016) confirmed that digital disruption is not a one-time event but a recurring trend over the past three decades, with different waves occurring across different market segments.

On the other hand, Karimi and Walter (2015) alleged that as digital technology evolves, they have the potential to demolish the competencies that underpin incumbents' existing business models. The researcher concluded that the advent of digitization causes path-dependent companies to undergo a digital transformation that benefits from a plethora of opportunities for business growth. According to Klang (2006), the advancement of technology does not seem disruptive until a larger number of users decide to adopt the technology. The tests on digital disruption conducted by Peteraf et al. (2013) revealed different insights on the transformative influence of new technologies. Bharadwaj et al. (2013) mentioned that recent work on digital disruption has focused on commercial prospects. According to the researcher, technological change creates new digital options for businesses to accelerate the institutional transformation and advance their businesses. According to Hill (2017), having the potential for digital disruption helps startups disrupt established organizations and alter enterprises more quickly than any historical force. Christensen (1997) claimed digital disruption is just a disruptive force for those who choose to ignore it or seek to combat it. Those who accept it also find it helpful to their company and lead them to success in a variety of ways. Skog et al. (2018) indicated that little attention has been given to the benefits digital disruption offers to modern businesses. In this study, continuous digital disruption was a continual change caused by the growth of digital technology and business models in an industry or organization that improves the value of new or existing goods and services (Skog et al., 2018).

\subsubsection{Perceived Ease of Use}

The founder of the Technology Acceptance Model (TAM), Davis (1989) defines Perceive Ease of Use as the degree to which a person expects the use of a given tool to be effortless (Radner and Rothschild, 2005). Al-Gahtani (2001) mentioned that researchers have concluded that perceived ease of use is the degree to which the user agrees that it will be at no cost to them by applying an exacting approach (Davis, 1989; Gefen and Straub, 2000). Rogers (1983) declared that the degree to which consumers consider a new product or service better than its alternatives is viewed as ease of use (Vagnani \& Volpe, 2017). Similarly, Davis (1989) confirmed that PEOU is an assumption that influences new technology adoption. Davis (1993) suggested that users' attitudes toward using technology are composed of a perceptual assessment of the interface functionality and an appropriate reaction to the system which affects the use or adoption of the technology. The researchers, stated that the greater the perceived ease of use of the device, the greater the likelihood of using the system. Davis (1993) also stated 
that PEOU assesses consumer expectations of usability and understanding. As a result, PEOU is concerned with consumer motivation, which is the intrinsic aspect of using technology. Zhang and Mao (2008) alleged that Perceived Ease of use is one main predictor of a consumer's drive to use or approve a product. Hornbæk and Hertzum (2017) reported that PEOU is concerned with user motivation of the inherent aspects of using technology, such as the interface and the mechanism involved in using it. The scholars stated that PEOU has no effects on technological acceptance because the extrinsic nature of technology is the reason people embrace technology.

Nonetheless, according to Nysveen et al. (2005a) PEOU will affect technology adoption because inherent features of the technology, such as architecture clarity and navigational ease, contribute to the importance of the outcome obtained by using the technology. In other words, people who consider the method to be beneficial develop behaviours towards the learning instrument. Davis' (1989) findings on the Technology Adoption Model (TAM) showed that consumers' understanding of ease of use had a positive impact on their desire to use new technologies. In the same way, Nysveen et al. (2005b) confirmed that customer understanding of ease of use affects the creation of strong customer convictions and the adoption of innovations. McFarland and Hamilton (2006) indicated that customer acceptance of innovations is directly relevant to the concept of ease of use. Venkatesh and Davis (2000) reported that perceived ease of use is an essential factor of the customer's willingness to agree and act in terms of use. His statement was also backed by Safeena et al. (2013) and Dohan and Tan (2013). On the contrary, Shoter et al. (2016) argued that perceived ease of use has a negative and significant impact on the use of a product or service. In this research, perceived ease of use was characterized as the magnitude to which an individual considers it effortless to use a particular service or product.

\subsection{Critical Review of Theories and Models}

\subsubsection{Technology Acceptance Model (Figure 1)}

The Technology Acceptance Model (TAM), developed by Davis (1989) explains why people want to use a particular technology in their work. The theory assumed that people use a particular technology because they find the technology useful and easy to use for the job. In the late 1980s, the idea was introduced as innovations such as e-mails and work processes which eliminated structures such as handwritten letters. Nevertheless, there is very little reference to this

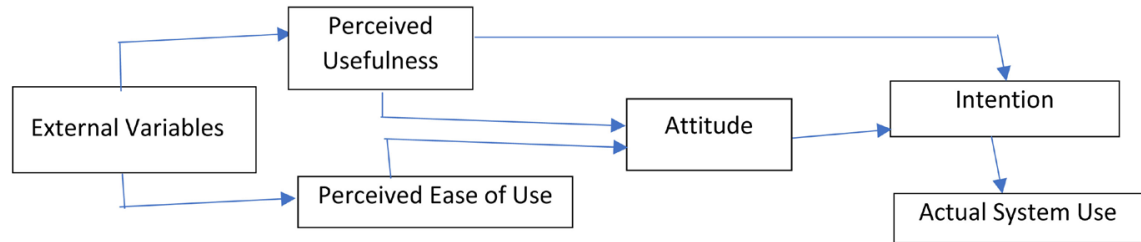

Figure 1. Schematic diagram of the technology acceptance model. 
theory concerning technology itself. The theory stated that the understanding of a single piece of technology varies by theory, not because the system is different, but because we are different.

One drawback of TAM theory is that it assumes that people plan their actions and that they are justified in their behaviour, which means that when people develop an attempt to use the model, they actually evaluate the means of usefulness and thereby use it in practice. The problem with this theory is that people do not make completely fair choices, nor are they logical in their behaviour. Another drawback of the theory is that it does not tell us how to make technology easy to use or useful. The theory only states that make sure that it is usable and user-friendly, it does not use any design guidance or show us how we can develop better systems than a general comment makes sure it's easy to use.

\subsubsection{Technology Acceptance Model 2 (Figure 2)}

Venkatesh and Davis (2000) introduced TAM 2 (or ETAM) as an extension of the original TAM due to the limitations of the TAM theory. Attitude was omitted in TAM 2, as variable and subjective norms related to social power was introduced (Park, 2012). The mechanism of social control and the same tooling distinguish the external variables in TAM 2 from each other. Venkatesh and Davis (2000) indicated that the perceived usefulness in many empiric TAMs depends on the user intentions and that the determinants of perceived usefulness need to be understood as it drives the use intentions and how these factors affect changes over time, with the increased use of the device. The integration of processes of social influence according to the scholars helps to decide whether a person will approve or reject a new product or service, while the Cognitive Instrumental Mechanism decides on the perceived ease of use, in terms of production, quality of production, and significance of work. The theory, in turn, indicates that each theory is good at explaining something, but they are not good at explaining certain things.

\section{- Diffusion of Innovation Theory (DOI)}

The Diffusion Invention Theory was developed more than 50 years ago by Rogers (1962). The theory is among the oldest theories of social science. It

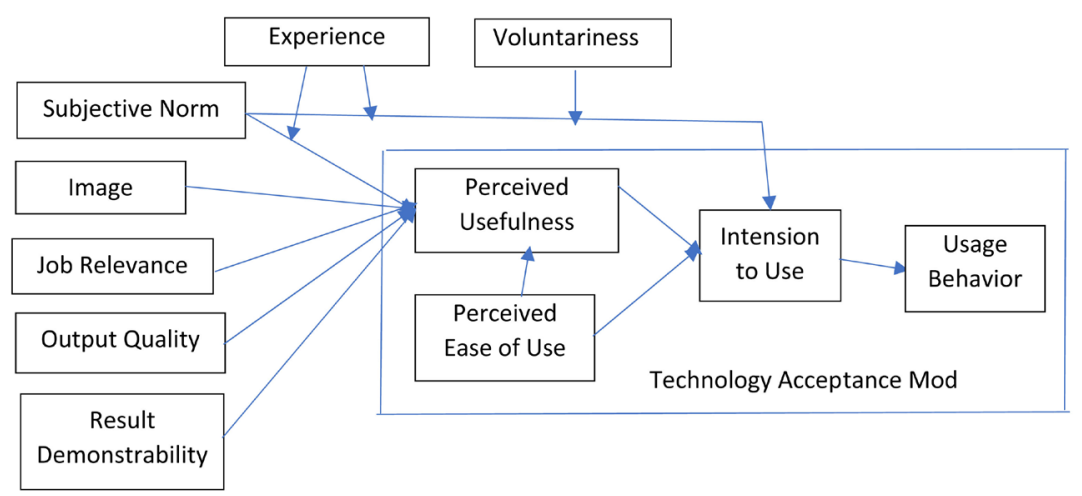

Figure 2. Technology acceptance model 2. 
originated in communication to illustrate how the idea or commodity gathers traction over time and spreads across a given population or social network. The author proposed five phases to clarify how to adjust innovation over time. The first category named Innovators consists of 2.5 percent of the segment. These are the people who want to try the product first. According to the researcher, these people are daring, they enjoy innovative concepts. To cater to this demographic, advertisers need to do very little or nothing. The second group according to the researcher is made up of approximately 13.5 percent of the segment, and they are called early adopters. These individuals represent opinion leaders. They appreciate leadership positions and welcome opportunities for change. These people are already aware of the need for improvement, so it is very easy for them to embrace new ideas. Strategies for catering to this community include the use of manuals and knowledge sheets for implementation. Early Majority is the third group to represent the next 34 percent of the segment. These individuals are rarely leaders, but they adapt to the new ideas of the average person. However, they usually need to see evidence that the product works before they can implement it. The fourth group is the Late Majority, which is made up of about 34 percent of the segment. Such people are wary of transition, and will only embrace innovation after it has been attempted by the majority. Strategies for appealing to this demographic is to provide details about how many others have attempted and successfully implemented the concept. In the fifth and final category are the Laggards, these people make up 16 percent of the segment. Traditionally these people are very old-fashioned. They are very cynical about transition, and they are the toughest people to get on board. Tactics to cater for this demographic consist of figures, fear petitions, and pressure from people in the other adopter classes. However, Everett Rogers mentioned that the stage at which an individual adapts innovation and achieves diffusion involves the recognition of the need for innovation, the choice to adopt (or reject) innovation, the initial use of the innovation to test it, and the constant use of the innovation (Figure 3).

\section{- The S Curve}

The S-curve was first used by Fisher \& Pry (1971), as a depiction of the evolution of a product. According to the S-curve theory, during the immediate launch of new technology, diffusion is said to be sluggish and rises at a low rate, reflecting

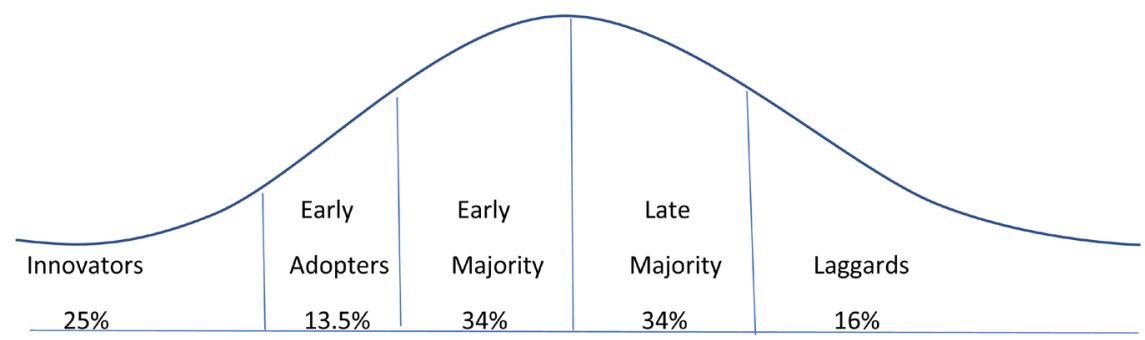

Figure 3. Diffusion of innovation theory. 
the comparatively slow rising portion at the beginning of the curve. Then, when the commodity becomes the industry standard, the major part of the potential market accepts the technology, and the pace of diffusion upsurges rapidly, signifying the middle part of the curve where it gets steep. Finally, the technology reaches its peak in the last phase. At this stage, all potential customers are seen using the new technology, and the diffusion reaches its peak at the end, which is represented by the S-curve becoming a horizontal line again. Tidd and Bessant (2018), used the S-curve for example, to explain the context of product dissemination, i.e. the mechanism through which the product concept is spread over time using certain networks and participants of the social networks. Tidd \& Bessant's interpretation portrays the S-curve as a pattern of a product's market penetration (Figure 4).

\subsubsection{Disruptive Innovation Theory}

The study of disruptive innovation theory draws its theoretical inspiration from innovation disruption theory by Christensen and Raynor. Disruptive innovation theory is a competitive reaction theory (Christensen et al., 2015). The disruption theory clarifies how well-established businesses leave themselves vulnerable to upstart competition by abandoning the lower end of the market. The four main elements of this theory are: 1) market leaders move along the path of sustainable innovation; 2) meeting customer needs; 3) being able to adapt to disruptive threats; and 4) the incumbent ends up floundering as a result of the disruption (Christensen et al. 2015; King \& Baatartogtokh, 2015).

According to Christensen and Raynor (2003), In the first aspect of the theory, successful managers seek to create better products that can be sold to unsatisfied customers in more profitable market segments with higher profit margins (ibid. 2013). The second component of Christensen and Raynor's theory is that the rate of innovation along the route of a clear value proposition always surpasses the consumer's readiness to use it at any level of the market. The theory suggests that a company whose products are firmly based on the current needs of conventional consumers could override what those customers will do or need in the future. In the third aspect, Christensen and Raynor conclude that existing

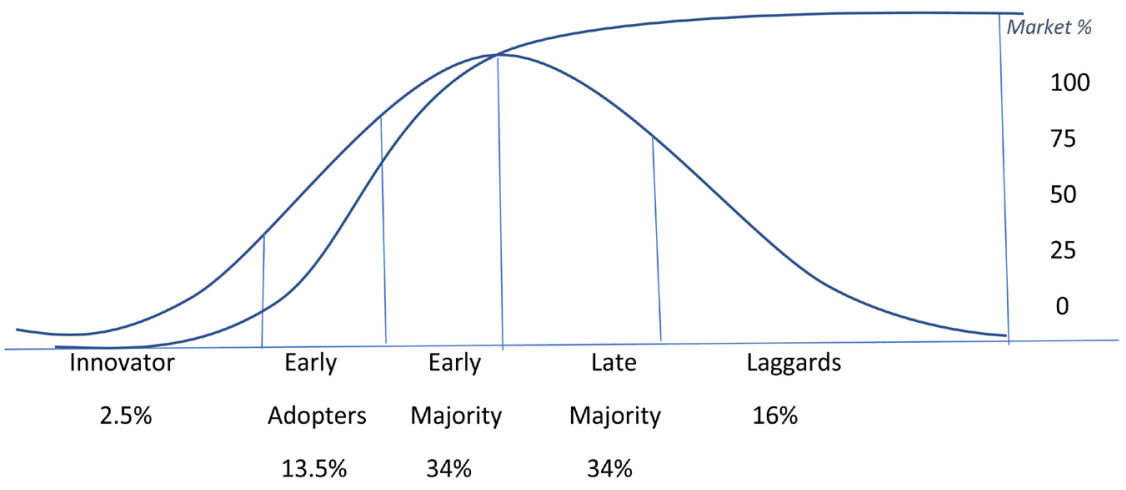

Figure 4. The $S$ curve of adoption of innovation. 
businesses already have the skills to thrive, but managers are unable to use those skills to combat potential disruptors. The researchers went on to demonstrate that these innovative goods from new entrants have different characteristics as they are tested against the value proposals of the incumbent companies when they launch goods that rely on the protection of innovation, usability, comfort, and cost-effectiveness. The scholars concluded that managers fail to comprehend the potential risk during that point in time to address the situation (Christensen \& Raynor, 2003). The last factor in the theory of disruptive technology or innovation is that the incumbents are floundering due to disruption. According to Christensen, companies with such innovations will often enhance the efficiency of their goods and thus ultimately take over the older markets (Figure 5).

\subsection{Empirical Review on Continuous Digital Disruption}

Despite widespread ignorance of its core concepts, the definition of digital disruptive has gained considerable global attention among practitioners (Elbanna \& Newman, 2016; Gartner Glossary, 2016; Legner et al., 2017; Gimpel et al., 2018; Parida, Sjödin \& Reim, 2019). Similarly, underlying disruption work has sparked regular citations and heated debate in academic circles, but empiric research barely discussed their central theoretical arguments because the theory of digital disruption poses some interesting contradictions, and the main principles of the theory are still widely ignored (Christensen et al., 2018). According to Von Briel et al. (2018) expedition and facilitation of a company's start-up cycle are among the advantages of digital disruption and emerging technologies. However, research has shown that the root cause of any disruptive technology or digital disruption in today's industry is the digitalization or development of digital technology (Dobbs et al., 2018). Christensen (1997) described digital disruption as an evolving technology based on conventional standards, with lower costs and better performance but higher auxiliary capacity. Ganguly et al. (2010), Palekar and Sedera (2012) reported that digital transformation is detrimental to the efficiency of media organizations as digital disruption or transformation can lead to job losses (Fairlie \& Fossen, 2018). On the other hand, their study found that

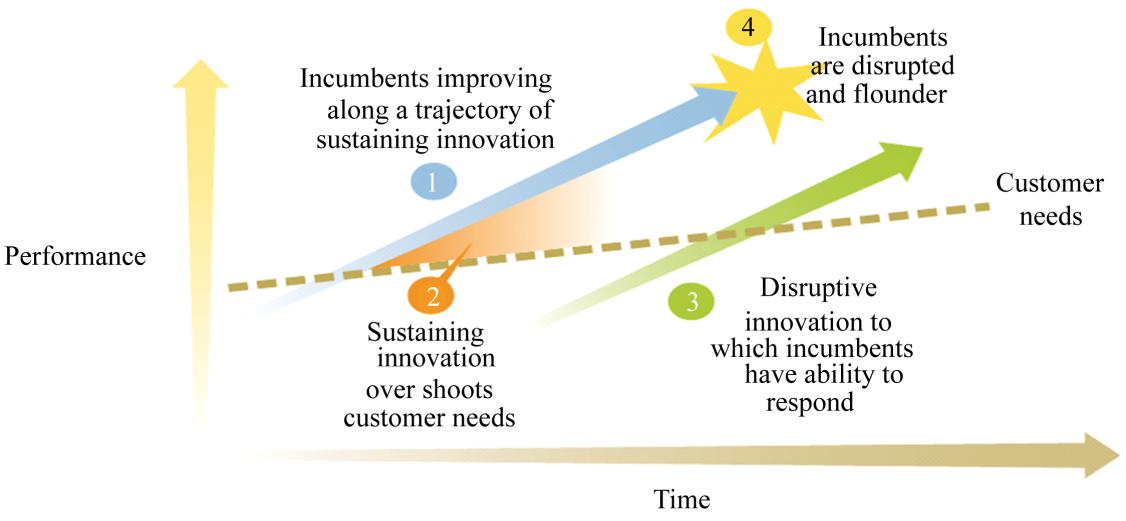

Figure 5. Illustrates the key ideas of the theory of disruption. 
organizational digitization could reduce the risk of human unemployment (Fossen \& Sorgner, 2018). Gartner Glossary (2018), argued that digitalization is the use of digital technology to transform the business model and create new ways to generate revenue and value.

Gobble (2018) contended that digitization is a simple process of transforming analogue to digital information that can lead to digital disruption. He also stated that digitization corresponds to the use of digital technologies to generate and extract value in new ways, and possibly in digitized information. Greeven et al. (2018) stated that digital disruption is the development of business models and processes that take advantage of digital opportunities. Rachinger et al. (2019) argued that digitization (i.e. the process of converting analogue data into digital data sets) is the basis for digital disruption, He further defined it as the exploitation of digital opportunities through the integration of various technologies (e.g. cloud technology, sensors, big data, 3D printing) that can open up new possibilities and potentially generate digital disruption. In this study, digital disruption is therefore the introduction of emerging technologies into all facets of the business, which radically alters the way the company operates and gives value to its clients. This digital transition continues to have an impact on companies, firms, and organizations in Malaysia. However, the advancement of technology, user expectations, and competitive pressure are factors described in this study as possible determinants of continuous digital disruption, using perceived ease of use role as a mediator.

\subsection{Literature Gap}

Although several researchers have been investigating key factors for digital disruption, such as the Internet of Things (IoT), cloud computing, big data, etc., the findings are still contradictory and inconclusive. Also, previous studies on digital disruptive or disruptive technologies focused on developed countries with wellestablished ICT and various aspects of digital disruption rather than technological advancement, competitive pressure, and user expectations on continuous digital disruption using perceived ease of use as a mediator (Legner et al., 2017; Fossen \& Sorgner, 2018; Parida et al., 2019). Teo et al. (2018) investigated digital disruption in Malaysian transport using Grab as a case study found that Grab car-sharing sweeps travellers and drivers from traditional taxi services to their systems through digital technology. Similarly, the World Bank (2018) asserts that Malaysia as a developing nation should not allow digitalization that has reduced the entire world to a miniature society pass them by. Consequently, resolving this research gap provides a significant opportunity for further studies. Elbanna and Newman (2016) indicated that the nature of digital innovation, digital transformation, and digital competitiveness should be further studied. Ganguly et al. (2010) suggested that further case studies should be used to test and verify disruptive technologies. Based on these recommendations, this study 
is carried out to add to the never-ending debate about the impact of technological advancement, competition pressure, and user expectations on continuous digital disruption, with perceived ease of use acting as a mediator. Below is a conceptual framework that reflects the correlation between the variables.

\subsection{Conceptual Framework and Hypothesis}

The following conceptual framework and assumptions were proposed to analyze the relationship between the independent, mediator, and dependent variables based on a detailed literature review of factors driving continuous digital disruption. To conclude, many studies have discovered that technological advancement, user expectations, and competitive pressure are important drivers of ongoing digital disruption, with perceived ease of use acting as a mediator (Table 1).

Similarly, continuous digital disruption was seen as putting companies and entrepreneurs on their toes causing them to come out with quality products at affordable prices for consumers. In the same way, continuous digital disruption gives companies new opportunities in their day-to-day operations, because perceived ease of use enhances the willingness of consumers to pursue digital disruption as they find it convenient to utilize the technological innovations they create (Figure 6).

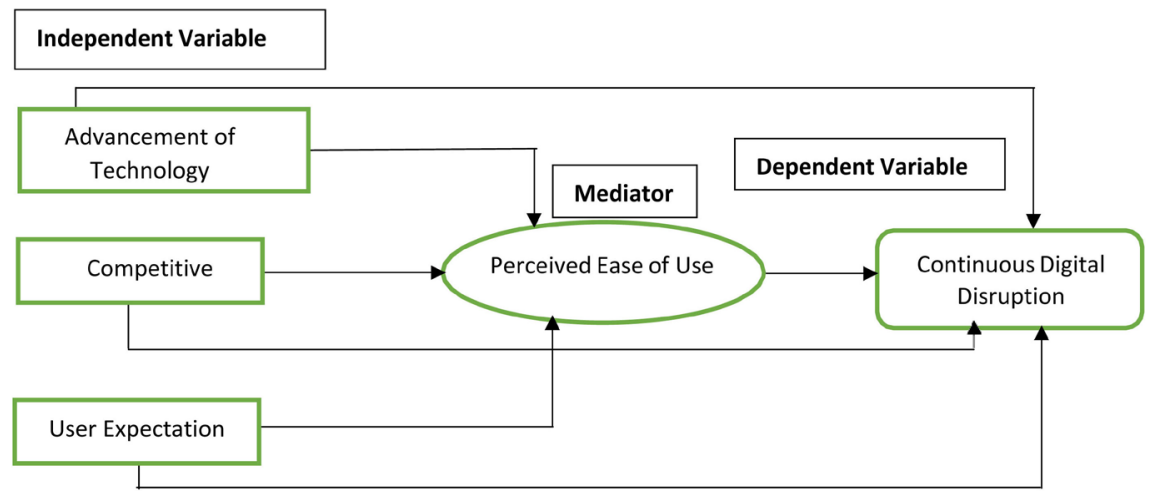

Figure 6. Conceptual framework.

Table 1. Proposed hypothesis for the conceptual model.

H1: Advancement of technology has a significant impact on continuous digital disruption

$\mathrm{H} 2$ : Competitive pressure has a significant impact on continuous digital disruption

H3: User expectation has a significant impact on continuous digital disruption

H4: Advancement of technology has a significant impact on perceived ease of use

H5: Competitive pressure has a significant impact on perceived ease of use

H6: User expectation has a significant impact on perceived ease of use

H7: Perceived ease of use as a mediator in the relationship between the Advancement of technology, Competition pressure, User expectation, and Continuous digital disruption. 


\subsubsection{Advancement of Technology on Continuous Digital Disruption}

Research has shown that one of the key factors contributing to the unceasing digital disruption that the world is experiencing today is the massive advancement of technology. The World Economic Forum (2017), has estimated statistically that as a result of technological advancement, 90 percent of the world's population will have access to the Internet, and by 2025 more than $50 \%$ of Internet traffic will go to household appliances and smartphones. According to Chui et al. (2016) rapid technology advancement growth could automate 45 percent of people's activities they pay to do, with other professions getting more than 30 percent of their constituent activities automated. The World Robotics Report (2016), also forecasted 2.6 million units by 2019. The report also stated that massive advances in cloud computing, the Internet of Things, data science, robots, drones, cognitive systems, the internet, computer devices, and communications technologies are key determinants of digital disruption. According to PwC (2017), the most recent technological revolution (artificial intelligence, robotics, and new software-enabled platforms) facilitating the high stakes in the global digital transformation game is currently in progress. Similarly, an Infosys Limited (2018), revealed that emerging technologies represent 86 percent of visionaries or entrepreneurs' largest determinants or drivers of continuous digital disruption. Another study conducted by Avanade Digital (2017), revealed that the key drivers of digital disruption are technology innovation. Results of the study further showed that over 12 months, approximately 48 percent of decision-makers state that adopting emerging technology is the main strategic goal of their company while raising productivity by 41 percent and enhancing safety by 34 percent. Bumann \& Peter (2016), confirmed that technological advancement has a far-reaching impact on digital disruption since big data and clouding dramatically reduce digital disruption-related costs. Bughin et al. (2017) also noted that technology advances can provide significant value that is not associated with work replacement which can allow companies to find new ways to identify customer needs, enhance operations through the use of predictive maintenance software, optimize work documentation and react quickly to changes that affect product quality. Chartered Accountants Australia \& New Zealand (2015) established that advancement of Technology has changed innovative issues and how business is conducted in the world today and has been disruptive. Therefore, the study predicts that:

H1: There will be a significant impact between advancement of technology and continuous digital disruption.

\subsubsection{Competitive Pressure on Digital Disruption}

In this research, competitive pressure was recognized as one of the main factors for continuous digital disruption. Competition pressure was described as the degree to which companies operate within the industry in a competitive atmosphere (Lertwongsatien \& Wongpinunwatana, 2003). Pfeffer and Leblebici (1977) showed that companies are likely to be creative in this competitive climate due 
to massive rivalry (Orlikowski, 2000). Reich and Benbasat (1990) claimed that companies disperse capital in a highly competitive market for the provision of creative goods or services for their customers. Tech Wire Asia (2018) also noted that today's digitally transformed environment presents new and unpredictable competitive challenges that companies need to survive and to succeed. Their survey showed that $90 \%$ of firms are facing increased competition from digital companies, either from existing rivals or new entrants. According to the scholars, many empiric studies have also shown that greater incentives motivate companies to accept innovation which results in higher competitive demand. Ford (2015) established that corporations need to incorporate Artificial Intelligence and robotics to remain competitive, as robots can do research faster and cheaper than humans. This finding indicates that there is a great link between competitive pressure and continuous digital disruption. Bughin and Van Zeebroeck (2019), research findings stated that across countries, digitization has a significant negative impact on the profits of incumbents through two loop effects: digital entrants competing with incumbents through disruptive models, and incumbents responding to disruption and creating more intense competition with each other. According to the scholars, these two loop effects suggest that organizations should go on the offensive as a successful digital strategy that is built on a scale larger than that of the rest of the industry yields the largest returns and may offset the full competitive impact of digitization. Their research further suggests companies should consider at least two dimensions when devising the type of bold reactions needed to compete: 1) concentrating on new customer segments rather than exclusively on current customers, and 2) focusing on new ways to re-segment the market, instead of relying solely on cost cutting and labour saving through automation. Therefore, the proposed hypothesis is accepted even though the significant impact was negative.

Also, scholarly research sources have identified a significant positive relationship between competitive pressures and continuous digital disruption. For instance, digital innovation was believed to present structural transition problems for sectors that have historically had little competition due to regulations such as taxis and short-term housing (Productivity Commission, 2016). The Productivity Commission's (2016) findings; reported that the implementation of emerging technologies translates into efficiency gains in terms of higher quality goods and increased competition. An external study conducted by Infosys Limited (2018) found that a major driver of digital disruption was market competition (76 percent). Rachinger et al. (2019) also found that digitization helped to make the sector more productive. This indicates a positive relationship between the digital transition and the competitiveness of the business. Lertwongsatien \& Wongpinunwatana (2003) examined the adoption of e-commerce in Thailand in the same year by small and medium-sized enterprises and found that users of e-commerce are more likely to implement disruptive innovations in an increasingly competitive climate. Therefore, the study predicts that: 
H2: There will be a significant impact between competitive pressure and continuous digital disruption.

\subsubsection{User Expectation on Digital Disruption}

In this study, the expectation of users or customers was also considered a determinant in continuous digital disruption. According to Verhoef et al. (2019), past studies have shown that consumer expectations have a huge effect on continuous digital disruption. Deloitte (2018) claimed that the boom in connectivity and information availability (digital disruption) has squarely placed consumers, staff, residents, patients, and others in the driver's seat. Maricar (2014) also found that user expectations in terms of ease of access, ease of payment, complete data, and protection have a positive impact on disruptive innovations. According to research, digital disruption and consumer expectations are moving hand in hand. These surveys reported 100 statistical data highlighting the success and value of digital transformation, its impact on consumer services, digital challenges, and opportunities for the future (Forbes, 2020). Krouskos et al. (2018) concluded that the market landscape is changing and that technological and digital technology developments do not only inspired customers but also allows businesses to collect, process, and interpret data in new ways to better inform strategic decisions and improve the way they work. According to the researcher, digital disruption has significantly helped the consumer. Tech Wire Asia (2018) stated that consumers are reshaping the industry and deciding how businesses work through various networks and geographical locations, and how quickly and efficiently businesses respond to their needs depends on keeping the technology running.

The findings of the survey conducted by Avanade Incorporation have also shown that $60 \%$ of respondents now state that consumers expect more advanced and personalized digital experience (Avanade Digital, 2017). McQuivey (2014) suggests that businesses need to digitally change their products and processes to improve their next customer experience. Similarly, an external report by Infosys Limited (2018) reported that the changing needs of end-users are among the main drivers of digital disruption. These results indicate a significant link between user expectation and continuous digital disruption. Therefore, the study predicts that:

H3: There will be a significant impact between user expectations and continuous digital disruption.

\subsubsection{Advancement of Technology \& PEOU}

The Technology Acceptance Model (TAM) is an extension of Ajzen and Fishbein's Reasoned Action Theory (TRA) (Priyanka and Kumar, 2013), a theory pioneered by Davis (1986), which has since undergone many modifications and validations. The theory seeks to explain factors that influence technological acceptance actions in the use of information technology, and a parsimonious theoretical explanatory model (Bertrand and Bouchard, 2008). Ducey and Coo- 
vert (2013) states that TAM requires perceived ease of use of a product because it is the primary determinant of user behaviour and technical acceptance. Teo (2013) also identified a variety of factors that encourage the use and acceptance of the technology. He explains human disparities, social conditions, beliefs, attitudes, and contextual triggers, such as perceived ease of use as factors that promote the inclination to use innovation and enhance the ability to accept or oppose it. Additionally, Teo (2013) argued that a person's actions are affected by a desire driven by perceived ease of use that heralds actual behaviour. According to Cascio \& Montealegre (2016), knowledge calls for the effective use of digital technology as technological innovation has become a weapon that facilitates access and the use of up-to-date knowledge tools to enhance efficiency and growth. Devanandan and Lakshmi (2018), argued that effective access to and use of information resources in the 21st century depends on the ability to use information technology tools efficiently. Adeniji et al. (2018), contended that failure to demonstrate expertise in this field could lead to technological resistance, which has been recognized as a key reason for impeding the introduction of new technologies in organizations. According to the World Economic Forum (2017) recognition of technological developments would lead to a better estimation of the use of new information technologies. The study of Alsamydai (2014), also shows that, due to perceived ease of use, confidence in the use of technology can lead to increased personal power, flexibility, and the correct use of knowledge. Thus, increased awareness of the ease of use of a product can, therefore, contribute to improved productivity. The World Forum (2017) also revealed that the inability to monitor and consider the use of emerging technologies or advances in technology could be daunting, which could ultimately lead to anxieties or the degree to which the standard of decision-making could be degraded in an organization. Therefore, the study predicts that:

H4: There will be a significant impact between advancement of technology and $P E O U$.

\subsubsection{Competitive Pressure and PEOU}

Competition pressure was identified as another effective driving force since the early stages of digital disruption research (Lippert and Govindarajulu, 2006; Lin and Lin, 2008). Zhu et al. (2006), described it as the magnitude of pressure that businesses feel from contenders in the industry. Industrial competition is typically seen as having a positive effect on the adoption of IT, particularly where innovation influences competition and the adoption of new technologies to contend in the market is a strategic necessity (Ramdani et al., 2009). Porter and Millar (1985) also mention that adopting information systems is useful when viewed as ease of use because it allows businesses to adjust their business landscape in terms of market rules according to the nature of the industry and the performance of their rivals (Melville et al., 2004). For example, the presence of key players in SMEs' external digital advancement setting such as government, competitors and a company's trading partners gives SMEs enough incentive to en- 
gage in internet marketing activities because of their perception of ease of use (Bruque \& Moyano, 2007; Awa et al., 2017). Similarly, these results are confirmed by past literature, in which much attention has been given to the impact of competitive pressure on the acceptance and use of technologies (Bruque \& Moyan, 2007; Dhurup \& Dlodlo, 2013). However, the findings relating to its effect remain conflicting. E-commerce research conducted by Premkumar and Roberts (1999) has shown that there is a positive correlation between competitive pressure and the adoption of new information technologies in rural small businesses because these technologies are user-friendly (Oliveira et al., 2016). Iacovou et al. (1995) emphasized this connection when it comes to introducing new technology in small businesses. By contrast, Thong (1999) found that economic rivalry had very little effect on the adoption of e-commerce by small businesses (Zhu et al., 2006). Since several studies claim that competitive pressure has a positive impact on the adoption of innovation as a result of perceived ease of use, it is assumed that competitive pressure has a significant positive impact on perceived ease of use. The analysis assumes that:

H5: There will be a significant impact between Competitive pressure and PEOU.

\subsubsection{User Expectation and PEOU}

Perceived ease of use has a strong relationship with consumer preferences according to Joo and Kim (2017). Researchers investigated PEOU in a variety of ways and proposed PEOU as a key component of technology model acceptance and continue use (TAM) (Davis, 1989; Moon \& Kim, 2001). Studies have also confirmed a positive relationship between consumer expectations and the perceived ease of use (Thong et al., 2006). Davis (1989) also maintains that PEOU is central to user awareness and cognitive belief in deciding user attitudes towards new technologies and behaviours to use (Thong et al., 2006). Numerous reports have shown that PEOU affects consumer preferences (Hong et al., 2006; Liao et al., 2007). Finally, Kujala et al. (2017), noted that preferences determine what a person wants to get from the service and are shaped by the needs of the client and the level of abstraction during the assessment process. Perceived ease of use from the Information Technology (IT) literature was described as a key building block for testing and evaluating user acceptance and expectations of a particular technology. Revels et al. (2010), confirmed that PEOU is a major motivating factor for consumers' desire to use technology. Pena-García et al. (2020), stated that, if consumers feel it is easy to use, their behaviour will be adapted to the new technologies. Amin et al. (2014), concluded that there is a positive relationship between PEOU and consumer expectations. Therefore, the analysis predicts that:

H6: There will be a significant impact between User expectation and PEOU.

\subsubsection{Perceived Ease of Use as a Mediator}

PEOU is interpreted as the extent to which users perceive the ease with which they participate in digital technology to promote their work or to access the cor- 
rect and useful information they need. PEOU is used in several forms, e-mail, e-commerce, $\mathrm{m}$-commerce, and wireless. PEOU is an element of recognition for emerging technologies (Damerji \& Salimi 2020). Wei et al. (2009) reported that the practicality of user-friendly technology will affect the target of initial implementation or continuity of an innovative product, regardless of whether the technology is perceived to be useful. Chong and Yahya (2014), concludes that $\mathrm{PEOU}$ is an intrinsic measure due to constant technological development since it is a major indicator of market acceptance for emerging technologies (Cheong and Park, 2005; Snowden et al., 2006). Hubert et al. (2018) argue that there is a close link between PEOU and technological advances. According to scholars, user expectation may be influenced by the ease of use of technology and indirectly influence user intention to implement it. This finding is further supported in the implementation of mobile networks (Hong et al., 2006; Lee and Chung, 2009; Mouakket, 2009).

Furthermore, previous studies have shown both direct and indirect effects of PEOU on the perceived value or intent of increasing smartphone users (Hubert et al., 2018). Davis (1989) suggested a constructive relationship between PEOU and consumer expectations. Davis (1989) in his research findings stated a constructive relationship between PEOU and consumer expectations. Past researches identified user expectation as having a significant impact on perceive ease of use. According to the scholars, user expectation may be influenced by the ease of use of technology and indirectly influence user intention to implement it. Their findings are further supported in the implementation of mobile networks (Hong et al., 2006; Lee and Chung, 2009; Mouakket, 2009). Ke et al. (2012) research findings reported that If user acceptance tests are performed the risk of user rejection could be reduced and preventive and predictive measures could be applied to ensure future user acceptance. In digital environments, scholars confirmed that user expectation positively influences Perceive ease of use (Joo \& Kim, 2017; Oghuma et al., 2016). Similarly, Kim and Forsythe (2010), emphasized that once the users' expectation with an initial experience is satisfied, they likely to use such services to maintain the cognitive balance. In the same way, Joo and Kim (2017), research findings concluded that user expectation has a significant correlation with perceive ease of use. Hence, these results indicate a significant link between user expectation and perceive ease of use. Competition pressure is another intrinsic measure among rival companies influenced by PEOU. Competitive pressure is also defined as the extent to which companies operate in a competitive atmosphere within the industry (Lertwongsatien \& Wongpinunwatana, 2003). Pfeffer and Leblebici (1977) revealed that companies are likely to implement innovation in this competitive environment because of intense competition, given that certain rivalry goods are considered more user-friendly than others. Reich and Benbasat (1990) suggested that an enterprise should be able to allocate resources to deliver new goods or services in an extremely harsh environment to respond to rivals when the rival company's prod- 
ucts are adapted because they are considered easy to use and useful (Ray et al., 2012). Most empirical studies have shown that higher opportunities for innovation are correlated with higher competitive pressures due to perceived ease of use of innovative goods. Lertwongsatien \& Wongpinunwatana (2003) found that e-commerce consumers are more likely to adopt new technology in a highly competitive market because they find it convenient to use. It is therefore proposed that PEOU should be positively linked to competitive pressure. Thus, the analysis predicts that:

H7: Perceived ease of use as a mediator in the relationship between the Advancement of technology, Competition pressure, User expectation, and Continuous digital disruption.

\section{Methodology}

\subsection{Introduction}

The aim of the research was to explore the impact of the advancement of technology, competitive pressure, user expectation on continuous digital disruption, using perceive ease of use role as a mediator in Kuala Lumpur Malaysia. This chapter is the methodology of the study. It consists of the Research paradigm, Research design and strategy, Data collection method, Data instrument, Target population, Sampling size and Sampling technique, Ethical issues and Accessibility, and Data analysis plan.

\subsection{Research Paradigm}

The study of literature by field experts contributes to a thorough understanding of the research paradigm's significance. For example, Kuhn (1962), an American philosopher was the one who used the term paradigm for the first time in the sense of scientific revolutions to denote a philosophical way of thinking. In Greek, the word has its aetiology, meaning pattern. Lather (1986) points out that, the research paradigm reflects the trust the researcher has in the world in which he/she lives and wants to live. He further stated that the way a researcher sees the world is guided by universal beliefs and concepts of how he/she interprets and behaves within the world. This means the research paradigm is the mirror that a researcher uses to see the world. According to Kivunja and Kuyini (2017), the Research paradigm is the theoretical context in which the researcher discusses the methodological aspects of the research project. Kivunja added that the research paradigm was defined by field pioneers as a specific set of behavioural or study-based beliefs or world views.

According to Saunders et al. (2016), research paradigm has four main distinct philosophies namely: positivism, interpretive, critical realism, and pragmatic. The researcher further stated that these philosophies can be further classified by an analysis of ontology, epistemology, and methodology. Ontology is essentially concerned with the nature of reality. Epistemology explains the relationship between the investigator and his interpretation of the evidence. Methodology is the 
different methods and techniques used to examine the study. According to Burrell and Morgan (2019), one of the pillars of research is the ability to explain the decision to accept or reject a theory. The scholars argued that, in order to properly assess the design, methodology, and interpretation of the research, it is important to understand these paradigms, their origins, and core values, to determine which one is suitable for the study.

Positivism research paradigm was chosen for the study because based on the research objective positivism is linked to established and extremely organized data collection methods since it is observable and measurable (Saunders et al., 2016). Another reason why this study chose positivism philosophy was that the analysis was purely quantitative and research has shown that positivism research philosophy is best suited for a purely quantitative study compared to an interpretive paradigm, critical realism paradigm and pragmatic paradigm where science can never be separated from its values and beliefs and ultimately can affect how data are collateral.

\subsection{Research Design and Strategy}

\subsubsection{Research Design}

Leedy (1997) describes research design as a study strategy that sets out the overall context for the collection of data and theoretical procedures with a strategic response structure or blueprint. Akhtar (2016), stated that research design is a strategic action mechanism that acts as a bridge between research issues and research strategies which have been developed or implemented. The scholar added that the word "research" is derived from the Latin word meaning learning (Blanche et al., 2006). Lastly Sileyew (2020), established that research designs use well-designed methodologies to collect data and analyse the results which disseminate the findings that lead to the generalization of information.

According to research, there are three types of research designs, namely exploratory, descriptive, and explanatory studies. Explanatory research design was chosen for this study because it emphasizes the link between cause and effect (Rahi, 2017). Research also indicated that study approach may be quantitative, qualitative, or mixed. The differences between quantitative (deductive) and qualitative (inductive) data are numerical and non-numerical; the mixed method, on the other hand, is made up of both quantitative method and the qualitative method (Weinreich, 2009). This research adopted the quantitative approach because the study aimed at testing theories, analysing evidence, illustrate the correlation between the variables, and to predict results (Weinreich, 2009). Saunders et al. (2016) stated that the use of quantitative data for data collection, such as a questionnaire, yields numerical data, whereas qualitative data, such as interviews, produces non-numeric data. The research methodology, therefore, adopted a quantitative approach, as the research seeks to explore the impact of technological advancement, competitive pressure, and user expectations on continuous digital disruption using perceiving ease of use role as a mediator in Kuala Lum- 
pur Malaysia.

\subsubsection{Research Strategy}

The research strategy is a step-by-step action plan that guides the thinking of researchers and their activities, enabling the researcher to carry out systematic and planned research to achieve consistent outcomes and detailed reporting (Shaw et al., 2018). Hiles added that research strategy aids the researcher to remain focused, reduce tension, improve quality, and saves time and money. According to Almalki (2016), Research design is the design of the researcher's bolts and nuts, outlining the rationale for the analysis and the experiments that the researcher must carry out in order to achieve the desired objectives. Saunders et al. (2016) reported that the research approach consists of exploration, survey, case study, ethnography, narrative research, grounded theory, action analysis, and archival research. According to literature, there are two main types of research strategies. They are cross-sectional and time series. A cross-sectional analysis strategy was adopted in this study. A cross-sectional analysis was adopted because according to Caruana et al. (2020), cross-sectional analysis consists of observations that can be done at a single point in time from different groups or individuals with similar characteristics. Cross-sectional analytical was selected because cross-sectional data can be extracted from quantitative data processing analysis using clear and accurate correlation analysis (Saunders et al., 2016).

\subsection{Data Collection Methods}

According to Sapsford and Jupp (2012), the process of data collection is the careful collection of the required facts, with the least possible manipulation, so that the study can provide accurately, and rational answers. Kabir (2016) described data collection method as a method for obtaining data from all available sources, in order to find answers to the research questions, testing the hypothesis, and evaluating the results. Levario et al. (2016) reported that the analysis of data is a systematic way of gathering and analysing information from a variety of sources to gain a complete and accurate image of the subject area.

According to literature, there are two main types of research-based data collection methods: primary data collection methods and secondary data collection methods. According to Saunders et al. (2016), Primary data collection is a method of gathering the original data or first data that the researcher specifically needs for the study. Examples of primary data include interviews, survey questionnaires, focus groups, observations, and experiments (Vijay \& Sharma, 2020). Secondary data collection is a source of data that has already been published in books, newspapers, magazines, blogs, and web portals, and so on. In this study, the primary data collection method was adopted and the survey questionnaire was identified as the best method for the data collection among the different types of primary data collection methods. The survey questionnaire was chosen for this study because, according to Sommer \& Sommer (2001), the survey ques- 
tionnaire examines the subject's views and can be self-governing. The data of this study was gathered using an online survey questionnaire (social media) which was developed using the Google survey form application. The survey questionnaire developed was distributed to the predefined sample size using WhatsApp. Respondents were requested to demonstrate their magnitude of agreement or disagreement on a 5-point Likert Style Statement which allowed the researcher to investigate the relationship between the variables and to explain the cause and effect of the relationship between the variables.

\subsection{Data Instrument}

According to Thomas (2016), Data instruments are data collection tools, machines, or processes. Lavrakas (2018) also mentioned that a paper questionnaire or a computerized interview are examples of data instruments. According to Kabir (2016), all forms of data collection include case studies, checklists, interviews, observations, and survey questionnaires. Glasow (2005) reported that data collection is aimed at collecting reliable evidence that helps researchers to provide convincing and accurate answers to the questions raised. Zohrabi (2013) concluded that the accuracy and reliability of any research project depend primarily on the appropriateness of the data collection tools used.

An online questionnaire was adopted in this research and a 5-point Likert scale ranging from 1 = "Strongly Disagree", 2 = "Disagree" 3 = "Uncertain", 4 = "Agree", 5 = "Strongly Agree" was chosen to measure all the variables because according to Taherdoost (2019), The 5-point Likert scale helps increase response rate and response efficiency and minimizes the frustration level of the respondents. The study also included demographic questions in the survey questionnaire because according to Sifers et al. (2002), Demographic questions allow researchers to obtain background information about their participants in the survey and better interpret their data. Similarly, Jung and Ejermo (2014) mentioned that common demographic questions used in research include age, gender, race, ethnicity, education, and employment, but may include any background features that the researcher considers to be important to the research project. Gender, age, nationality, marital status, educational level, occupation, work position, and range of monthly income are demographic issues used in this study.

\subsection{Target Population}

The target population, according to Ary, Jacobs, and Rezavieh (2002), refer to the whole group of people to whom the results of the study are related. According to Bartlett et al. (2001), the target population is a subset of a real or hypothetical set of individuals, events, or artifacts that the scholar wants to extrapolate to the findings of the study. The target population for this research consists of people 18 years of age and older in Kuala Lumpur Malaysia using or working with digital technologies. 


\subsection{Sample Size and Sampling Method}

The size of the sample according to Saunders et al. (2016), is a relatively small and a subset of the target group that accurately reflects the overall group, and allow the population as a whole to obtain an accurate (within reasonable limits) image of the different aspects of the study interest. The researchers declared that data from the entire population would be difficult to obtain; so, all study issues need to be addressed by selecting a sample size. In this research, 300 sample size was chosen, so 300 questionnaires were distributed but 292 valid questionnaires were received from respondents. This sample size was considered suitable for the research because Roscoe (1975) gave a "rule of thumb" for determining the size of a sample. The scholar stated that a sample size larger than 30 and smaller than 500 is appropriate for most studies under Roscoe's rule of thumb. As such, the 234 responses received were considered to be an appropriate sample size for the study.

According to research, there are two types of sampling techniques, namely probability and non-probability sampling techniques. Trochim \& Donnelly (2006) defined Probability sampling methods as a random selection from a population of statistical samples. Taherdoost (2016), also mentioned that in the probability tests, each case is deliberately chosen from the target population and each sample had the same chance that the researcher would predict the statistics and characteristics of the target population. Random sampling, systematic sampling, stratified sampling, and clustered sampling are examples of probability sampling. In Non-probability samples, each case of the sample is not assumed or chosen for the target population and therefore cannot have statistical characteristics for the target population (Saunders et al., 2016). Convenience sampling methods, quota sampling methods, purposeful sampling methods, and snowball sampling methods are examples of non-probability sampling methods. In this analysis, due to ease of accessibility and low cost, the non-probability sampling method was preferred for the data collection and convenience sampling, which is one of the types of non-probability sampling methods was used to collect the data because according to Saunders et al. (2012), Convenience sampling is a sampling procedure where the first available primary data source is used for the analysis without additional parameters. The scholars mentioned that with this type of sampling, participants can be located anywhere they are found, and wherever they are convenient (Showkat \& Parveen, 2017).

\subsection{Ethical Issues and Accessibility}

Research ethics relates to behavioural norms that regulate the conduct of a researcher in the interests of those who are subjects of the study or who are influenced by the study (Saunders et al., 2016). According to Brannmark and Sahlin (2010), Ethical philosophy calls for justice, dignity, and respect for others. Zolkefli (2020) professed that researchers have a moral obligation to carry out accurate and honest analysis of their results. The scholar also described infringe- 
ments of data as unethical and incompetent on the part of the researcher. The ethical values considered in this research include autonomy, privacy, and confidentiality, along with a guarantee that the researcher would not transmit any of the data collected or manipulate any of the data collected from the respondents. Data were accessed and collected using an online survey questionnaire developed using Google survey questionnaire form. The developed survey questionnaire link was distributed to individuals on group platforms through WhatsApp. As this research survey focuses on self-selected convenience, respondents were not forced to participate in the survey but were allowed to partake in the survey solely based on their willingness to participate. The survey took approximately two weeks to gather 234 valid survey responses.

\subsection{Data Analysis Plan}

The data collected through the primary source questionnaire were analysed using SPSS AMOS (Arbuckle, 2013), in this study, two analyses were conducted. They are confirmatory factor analysis and structural equation modelling. The analysis of the data conducted has three objectives: to make the data appear better, to test the data value, and to test the research hypotheses (Sekaran and Bougie, 2013). Confirmatory factor analysis was carried out to test the research hypotheses and to help the researcher confirm or reject the measurement theory by summarizing the basic results to encourage understanding for both the researcher and the reader. The confirmatory analysis was also carried out to check if the measurements of the construct are inconsistent with the researcher's understanding of the existence of the constructs (or factors) because the purpose of the confirmatory factor analysis was to evaluate if the data match the hypothesized measurement model (Campbell \& Fiske, 1959). Additionally, the data collected and analysed using the confirmatory factor analysis, was used as a representation of the respondent's sense of interest and therefore, was used as categorical data in the frequency tables to determine the relationship between the variables.

Structural equation analysis was carried out in order to check the reliability, validity, and complexity of the study. Reliability statistics was used to calculate reliability and accuracy using Cronbach's alpha, a reliability metric that shows how well the artifacts in a sequence are positively correlated with each other (Sekaran and Bougie, 2013). Inferential statistics was used to check the current hypotheses and to answer the research questions. These approaches were therefore used in this study to determine the impact of the three independent variables and one mediating variable on the dependent variables. This means that the analysis of the confirmatory factor and the analysis of the structural equation modelling was used to assess the impact of advancement of technology, competitive pressure, and user expectations on continuous digital disruption using perceive ease of use role as a mediator. 


\section{Results and Discussion}

\subsection{Research Result Findings, Research Analysis and Discussion on the Analysis}

This chapter addressed the findings and analysis from 292 survey questionnaires obtained from the target population, 18 years or older, working with digital technologies in Kuala Lumpur (Malaysia), through an online survey. Respondents were, assessed on the research topic: impact of advancement of technology, competitive pressure, and user expectations on continuous digital disruption using perceive ease of use role as a mediator in Kuala Lumpur (Malaysia).

After data collection, a series of data analyses were carried out, starting with demographic analysis, reliability, and normality testing using SPSS 22 statistical software. Subsequently, AMOS 22 was used to establish a causal relationship between the variables; using Factor Exploration Analysis (EFA), Confirmatory factor analysis (CFA), Discriminant, and Convergent Validity Measurement, Structural Equation Model (SEM) and Path Analysis.

\subsection{Demographic Analysis}

Demographic questions allow researchers to obtain background information about their participants in the survey. Such questions provide a framework for the data obtained from the study, enabling researchers to identify their participants and better interpret their data (Hauser and Duncan, 1972). Similarly, Jung and Ejermo (2014), mentioned that common demographic questions used in research include age, gender, race, ethnicity, education, and employment, but may include any background features that the researcher considers significant to the research project. The demographic issues used in this study were gender, age, occupation, and monthly income range, as shown in Table 2.

A total of 300 questionnaires were administered to the target population via an online survey, and 292 correct and accurate responses were provided for the study, reflecting a response rate of $97.33 \%$. The gender profile shows that the majority of respondents were male $52.4 \%, 46.2 \%$ female, and $1.4 \%$ who preferred not to say so. The age distribution data showed that the age group of $25-34$ had the highest response rate of $33.2 \%$, followed by the age group of $18-24$, representing $30.8 \%$, followed by the age group of $35-44$, representing $26.7 \%$, followed by the age group of $45-54$, representing $8.6 \%$, and lastly the age group of 55 , representing $0.7 \%$ and above. The data collected showed that $37.0 \%$ of respondents were employed, $0.7 \%$ were retired, $13.7 \%$ were self-employed, $45.2 \%$ were students and $3.4 \%$ were unemployed. The monthly household income range of respondents showed that $6.8 \%$ of income were higher than RM 10, 000, 63.4\% of income; were between RM 2000 - 4000, 14.0\% of income; were RM 4001 - RM 6000, 8.9\% of respondent's income; were between RM 6001 8000 and lastly, $6.8 \%$ of respondent's income; were between RM 8001 - RM 10, 000. 
Table 2. Demographic statistics of the respondents' profile.

\begin{tabular}{|c|c|c|c|c|}
\hline Gender & Frequency & Percent & Valid Percent & Cumulative Percent \\
\hline Female & 135 & 46.2 & 46.2 & 46.2 \\
\hline Male & 153 & 52.4 & 52.4 & 98.6 \\
\hline Prefer not to say & 4 & 1.4 & 1.4 & 100.0 \\
\hline Total & 292 & 100.0 & 100.0 & \\
\hline Age Group & Frequency & Percent & Valid Percent & Cumulative Percent \\
\hline $18-24$ years & 90 & 30.8 & 30.8 & 30.8 \\
\hline 25 - 34 years & 97 & 33.2 & 33.2 & 64.0 \\
\hline 35 - 44 years & 78 & 26.7 & 26.7 & 90.8 \\
\hline 45 - 54 years & 25 & 8.6 & 8.6 & 99.3 \\
\hline 55 years and above & 2 & 0.7 & 0.7 & 100.0 \\
\hline Total & 292 & 100.0 & 100.0 & \\
\hline Occupation & Frequency & Percent & Valid Percent & Cumulative Percent \\
\hline Employed & 108 & 37.0 & 37.0 & 37.0 \\
\hline Retired & 2 & 0.7 & 0.7 & 37.7 \\
\hline Self-employed & 40 & 13.7 & 13.7 & 51.4 \\
\hline Student & 132 & 45.2 & 45.2 & 96.6 \\
\hline Unemployed & 10 & 3.4 & 3.4 & 100.0 \\
\hline Total & 292 & 100.0 & 100.0 & \\
\hline Income & Frequency & Percent & Valid Percent & Cumulative Percent \\
\hline Above RM 10, 000 & 20 & 6.8 & 6.8 & 6.8 \\
\hline RM 2000 - RM 4000 & 185 & 63.4 & 63.4 & 70.2 \\
\hline RM 4001 - RM 6000 & 41 & 14.0 & 14.0 & 84.2 \\
\hline RM 6001 - RM 8000 & 26 & 8.9 & 8.9 & 93.2 \\
\hline RM 8001 - RM 10, 000 & 20 & 6.8 & 6.8 & 100.0 \\
\hline Total & 292 & 100.0 & 100.0 & \\
\hline
\end{tabular}

\subsection{Data Normality Analysis}

Normality analysis is used in statistics to assess whether the data collection is well represented by a normal distribution and to measure how likely a random variable would normally be distributed under the data set (Ghasemi and Zahediasl, 2012). Normality analysis can be in the form of Graphical approaches which include the histogram and plot of normality and statistical approach, which is made up of two numerical shape measurements-skewness and excess kurtosis. According to research, the Normality test's skewness measures the symmetry of data distribution, and kurtosis measures flatness and peakness of data distribution. Research also states that if skewness is not close to zero, then the data set will not be distributed normally (Ahad et al., 2011). In this study, normality testing was performed using a statistical method to assess whether the 
sample data collected from the survey were normally distributed to draw a reliable and accurate conclusion (Ghasemi and Zahediasl, 2012).

The findings of the normality test for all variables in these studies are shown in Table 3. According to Hair Jr. et al. (2010) and George \& Mallery (2010), the variable is relatively similar to the average if the normality measurement skewness and kurtosis are between -1.0 and +1.0 , respectively. This is considered the rule of thumb for excellence. The normality test results showed mainly the normal distribution of the variables in this analysis. Except for some few variables

Table 3. Normality test with descriptive statistic.

\begin{tabular}{|c|c|c|c|c|c|c|c|}
\hline \multicolumn{8}{|c|}{ Descriptive Statistics } \\
\hline & \multirow{2}{*}{$\frac{\mathrm{N}}{\text { Statistic }}$} & \multirow{2}{*}{$\begin{array}{c}\text { Mean } \\
\text { Statistic }\end{array}$} & \multirow{2}{*}{$\begin{array}{c}\text { Std. Deviation } \\
\text { Statistic }\end{array}$} & \multicolumn{2}{|c|}{ Skewness } & \multicolumn{2}{|c|}{ Kurtosis } \\
\hline & & & & Statistic & Std. Error & Statistic & Std. Error \\
\hline AT1 & 292 & 4.534 & 0.5582 & -0.673 & 0.143 & -0.601 & 0.284 \\
\hline AT2 & 292 & 4.021 & 0.9229 & -0.833 & 0.143 & 0.213 & 0.284 \\
\hline AT3 & 292 & 4.346 & 0.6477 & -0.557 & 0.143 & -0.285 & 0.284 \\
\hline AT4 & 292 & 3.993 & 0.9342 & -0.801 & 0.143 & 0.214 & 0.284 \\
\hline AT5 & 292 & 4.401 & 0.6531 & -1.006 & 0.143 & 1.475 & 0.284 \\
\hline UE1 & 292 & 4.305 & 0.6883 & -0.863 & 0.143 & 0.982 & 0.284 \\
\hline UE2 & 292 & 4.024 & 0.7572 & -0.662 & 0.143 & 1.007 & 0.284 \\
\hline UE3 & 292 & 3.976 & 0.9097 & -0.752 & 0.143 & 0.147 & 0.284 \\
\hline UE4 & 292 & 4.068 & 0.7747 & -0.744 & 0.143 & 0.772 & 0.284 \\
\hline UE5 & 292 & 4.212 & 0.7480 & -1.062 & 0.143 & 1.814 & 0.284 \\
\hline $\mathrm{CP} 1$ & 292 & 4.452 & 0.6589 & -1.165 & 0.143 & 1.679 & 0.284 \\
\hline $\mathrm{CP} 2$ & 292 & 4.271 & 0.8406 & -1.385 & 0.143 & 2.423 & 0.284 \\
\hline $\mathrm{CP} 3$ & 292 & 4.079 & 0.9217 & -1.032 & 0.143 & 0.884 & 0.284 \\
\hline $\mathrm{CP} 4$ & 292 & 4.397 & 0.6934 & -1.215 & 0.143 & 2.314 & 0.284 \\
\hline CP5 & 292 & 4.212 & 0.7662 & -0.751 & 0.143 & 0.431 & 0.284 \\
\hline PU1 & 292 & 2.966 & 1.2513 & 0.235 & 0.143 & -1.121 & 0.284 \\
\hline PU2 & 292 & 3.979 & 0.8927 & -0.923 & 0.143 & 0.880 & 0.284 \\
\hline PU3 & 292 & 3.979 & 0.9003 & -0.671 & 0.143 & -0.235 & 0.284 \\
\hline PU4 & 292 & 4.168 & 0.7661 & -0.849 & 0.143 & 0.961 & 0.284 \\
\hline PU5 & 292 & 4.120 & 0.7480 & -0.645 & 0.143 & 0.312 & 0.284 \\
\hline DD1 & 292 & 3.997 & 0.8102 & -0.540 & 0.143 & -0.117 & 0.284 \\
\hline DD2 & 292 & 4.130 & 0.7252 & -0.584 & 0.143 & 0.264 & 0.284 \\
\hline DD3 & 292 & 3.880 & 0.9134 & -0.632 & 0.143 & -0.052 & 0.284 \\
\hline DD4 & 292 & 3.959 & 0.8112 & -0.547 & 0.143 & 0.146 & 0.284 \\
\hline DD5 & 292 & 3.798 & 0.8597 & -0.480 & 0.143 & 0.016 & 0.284 \\
\hline Valid N (listwise) & 292 & & & & & & \\
\hline
\end{tabular}


such as AT5 which showed (-1.006) of skewness and (1.475) of Kurtosis, UE5 also showed $(-1.062)$ of skewness and (1.814) of Kurtosis, CP1 showed (-1.165) of skewness and (1.679) of kurtosis, CP2 showed (-1.385) of skewness and (2.423) of kurtosis, CP3 showed (-1.032) of skewness and a normal kurtosis, CP4 showed $(-1.215)$ of skewness and a standard error of (0.143) and (2.314) kurtosis. PU1 on the other hand showed a normal skewness and (-1.121) Kurtosis. The skewness statistic in this study shows an overall satisfactory normal distribution except for six variables in the analysis. Also, Kurtosis statistics in this study showed that the overall normal distribution was satisfied, except for six of its variables which were outside the normal distribution of -1 to +1 .

Hair Jr. et al. (2014), however, reported that the value of skewness and kurtosis is considered acceptable if the values are reasonably closed to the normal range. The value of two variables in this analysis was not within the range but was closed to -1 these variables were AT5 with skewness value of $(-1.006)$ and CP3 with skewness value of (-1.032). Similarly, research has shown that the score for skewness and kurtosis in the normality test ranges from -2.0 to +2.0 in normal univariate distribution (Trochim \& Donnelly, 2006; Gravetter \& Wallnau, 2014). Ghasemi and Zahediasl (2012) and Hair Jr. et al. (2014) state that in research with a large sample size (200 and above) small standard errors in normality tests may occur, even if the impact is insignificant. Therefore, based on these findings the skewness and kurtosis analysis of this research were considered acceptable, except for two kurtosis variables with values above +2.0 , they are CP2 with a value of (2.423) and CP4 with a value of (2.314). Westfall (2014) claimed that high kurtosis means that rare extreme deviations cause variation, as opposed to moderate-scale deviations. A reliability check was, therefore, carried out to determine the reliability of these variables.

\subsection{Confirmatory Factor Analysis}

Confirmatory Factor Analysis (CFA) is a statistical multivariate technique used to check how well the variables calculated reflect the number of constructs (Lance \& Vandenberg, 2002). Confirmatory factor analysis (CFA) is a method used to maintain or refute the principle of measurement. The purpose of the confirmatory factor analysis is to test if the data fit the hypothesized model of measurement Ozkok et al. (2019). Campbell \& Fiske (1959) stated that Jöreskog initially created CFA to replace older methods such as the MTMM Matrix (Kyriazos, 2018). CFA is composed of four main characteristics, according to Brown (2006): Testing Measurement Invariance, Testing Method Measures, Construct Validation, and Psychometric Evaluation Measures. The study used confirmatory factor analysis using AMOS 22 software to analyse whether the proposed model was suitable or fits the factor loadings indices, such as Degrees of Freedom (DF), Chi-Square Test, Comparative Fit Index (CFI), p-value, Normed Chi-Square and Root Mean Square Error of Approximation (RMSEA). Table 4 sets out the suggested thumb rule for assessing the acceptability and consistency 
Table 4. Summary of the acceptable index for confirmatory factor analysis.

\begin{tabular}{ccccc}
\hline $\begin{array}{c}\text { Name of } \\
\text { category }\end{array}$ & $\begin{array}{c}\text { Name of } \\
\text { Index }\end{array}$ & Index full Name & $\begin{array}{c}\text { Level of } \\
\text { Acceptance }\end{array}$ & Literature \\
\hline $\begin{array}{c}\text { Absolute } \\
\text { Fit Indices }\end{array}$ & RMI & Goodness-of-fit Index & $>9.0$ & $\begin{array}{c}\text { Maiti and } \\
\text { Mukherjee (1991) }\end{array}$ \\
& $\begin{array}{c}\text { Normed } \\
\text { Chi-Square }\end{array}$ & $\begin{array}{c}\text { Root Mean Square } \\
\text { Error of Approximation }\end{array}$ & $0.03-0.08$ & $\begin{array}{c}\text { Hu and } \\
\text { Bentler (1999) }\end{array}$ \\
& NFI & Normed Fit Index & $>0.9$ & Hair Jr. et al. (2014) \\
\hline $\begin{array}{c}\text { Incremental } \\
\text { Fit Indices }\end{array}$ & TLI & Tucker Lewis Index & $>0.9$ & Hair Jr. et al. (2014) \\
& CFI & Comparative Fit Index & $>0.9$ & Hair Jr. et al. (2014) \\
& RNI & Relative Noncentrality Index & $0-1$ & Hair Jr. et al. (2014) \\
\hline $\begin{array}{l}\text { Parsimony } \\
\text { Fit Indices }\end{array}$ & PNFI & Parsimony Normed Fit Index & $>0.9$ & Wheaton et al. (1977) \\
\hline
\end{tabular}

of the data sample in the confirmatory factor study (Hair Jr. et al., 2014) (Figure 7).

The CFA result shows that the model for this study appears to be justified and acceptable as a good fit model with all values within the acceptability level. According to Barrett (2007), 0.000 Chi-square values were statistically relevant for the overall model-fit assessment of this study. RMSEA result 0.081 indicates that this study's model was good because $\mathrm{Hu}$ and Bentler (1999) mentions that RMSEA values ranging from 0 to 1 are a good fit for a model with lower values indicating better fitness. Hence, the 0.081 RMSEA value was deemed suitable for the model (Hooper et al., 2008). Normed Chi-Square was 2.901. The value of the normed chi-square should be less than 3.0 according to the thumb rule. As a result, the outcome satisfied the thumb rule, indicating a good fit between the sample data and the hypothesised model (Kline, 2005). However, the value of the Comparative Fit Index (CFI) was 0.833 . The CFI value was justified by acceptance using the rule of thumb that states that CFI should be within $0.0-1.0$.

According to the thumb rule, a statistical range between 0.0 and 1.0 with a value close to 1.0 indicates a good fit (Hooper et al., 2008). The cut-off criterion as a rule of thumb for CFI 0.90 was a good fit, while CFI $>0.80$ was the lowest threshold for acceptable cut-off values (Bentler \& Bonnet, 1980; Bentler, 1990). The CFI value $>0.80$ was accepted based on the criteria of $>0.90$ but can be rejected based on an excellent threshold of $>0.95$. Therefore, the effect of the cut-off values on model acceptance was essential for incremental fit indexes (Beauducel \& Wittmann, 2005). No additional magnified variables have been eliminated as all 24 magnification variables explain the total and significant variance to be included in the model to analyse the result predictions of the variables effectively (Table 5). 


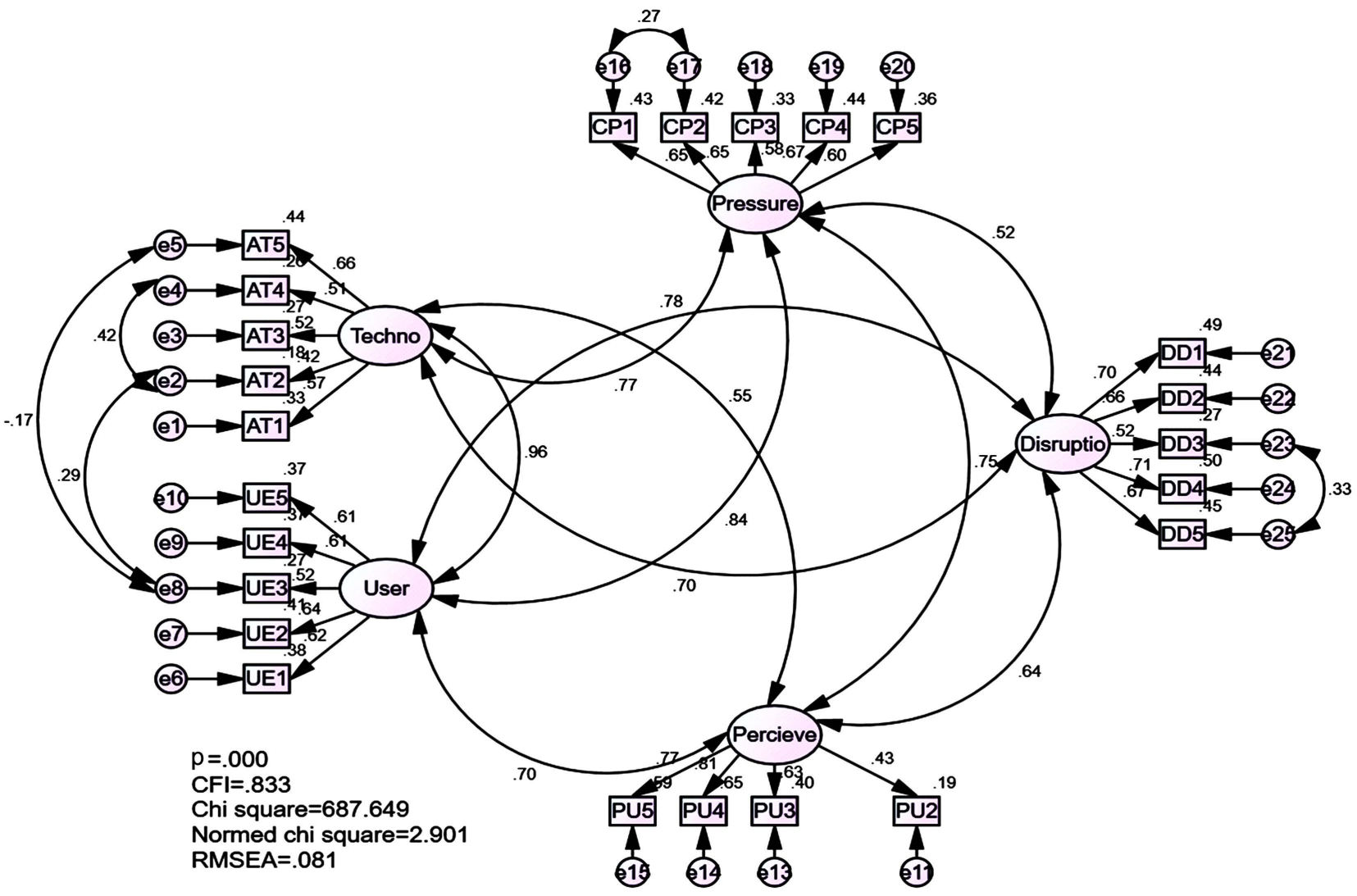

Figure 7. Modified confirmatory factor analysis on hypothesis model.

Table 5. Summary results for confirmatory factor analysis.

\begin{tabular}{ccc}
\hline Name of Index & Level of Acceptance & CFA Result Index \\
\hline Chi-Square ( $p$-Value) & $<0.05$ & 0.000 \\
Comparative Fit Index (CFI) & $>0.9$ & 0.833 \\
Root Mean Square Error of Approximation (RMSEA) & $0.03-0.08$ & 0.081 \\
Normed Chi-Square & $<3$ & 2.901 \\
\hline
\end{tabular}

\subsection{Divergent Validity Measurement}

According to Siddaway et al. (2017), the divergence of validity allows researchers to verify that two different tests can be considered independent. According to the researcher, one way to interpret separate data as independent is to prove that they characterize two unique constructs. The researcher refers to this as the divergence of validity. Similarly, Campbell \& Fiske (1959) reported that the Divergence Validity Analysis is used to assess whether the survey provided the expected opposite result for the researcher to answer the question and how the researchers wanted it to be answered (John \& Benet-Martinez, 2000). According to the researchers, a positive discriminatory validity evaluation suggests that the concept test is not strongly correlated with other measures designed to evaluate specific concepts (Ursachi et al., 2015). The results of the divergent validity test of this study are in Table 6 below. 
Table 6. Results for divergent validity measurement.

\begin{tabular}{|c|c|c|c|c|c|}
\hline \multicolumn{6}{|c|}{ Divergent Validity Measurement } \\
\hline Constructs & $\begin{array}{l}\text { Advancement } \\
\text { of technology }\end{array}$ & $\begin{array}{c}\text { User's } \\
\text { Experience }\end{array}$ & $\begin{array}{l}\text { Competitive } \\
\text { Pressure }\end{array}$ & $\begin{array}{c}\text { Perceived } \\
\text { Ease of Use }\end{array}$ & $\begin{array}{c}\text { Continuous } \\
\text { Digital } \\
\text { Disruption }\end{array}$ \\
\hline AT1 & 0.570 & & & & \\
\hline AT2 & 0.419 & & & & \\
\hline AT3 & 0.522 & & & & \\
\hline AT4 & 0.510 & & & & \\
\hline AT5 & 0.662 & & & & \\
\hline UE1 & & 0.615 & & & \\
\hline UE2 & & 0.640 & & & \\
\hline UE3 & & 0.516 & & & \\
\hline UE4 & & 0.610 & & & \\
\hline UE5 & & 0.611 & & & \\
\hline $\mathrm{CP} 1$ & & & 0.654 & & \\
\hline $\mathrm{CP} 2$ & & & 0.648 & & \\
\hline $\mathrm{CP} 3$ & & & 0.579 & & \\
\hline $\mathrm{CP} 4$ & & & 0.666 & & \\
\hline CP5 & & & 0.604 & & \\
\hline PU2 & & & & 0.431 & \\
\hline PU3 & & & & 0.634 & \\
\hline PU4 & & & & 0.808 & \\
\hline PU5 & & & & 0.769 & \\
\hline DD1 & & & & & 0.699 \\
\hline DD2 & & & & & 0.663 \\
\hline DD3 & & & & & 0.522 \\
\hline $\mathrm{DD} 4$ & & & & & 0.709 \\
\hline DD5 & & & & & 0.672 \\
\hline Average variance & 0.536 & 0.598 & 0.630 & 0.660 & 0.653 \\
\hline Reliability test & 0.682 & 0.728 & 0.769 & 0.735 & 0.802 \\
\hline
\end{tabular}

According to Hair Jr. et al. (2010), the thumb rule for Divergent Validity factor loading should be above 0.5 , and on average below 1.0. As shown in Table 6, almost all 24 observed variables, standardized factor loadings were $>0.5$ which means that the variables were within the acceptable validity requirement (Hair Jr. et al., 2006), except for two variables AT2 (0.419) and PU2 (0.431). Excluding the two outliers, the average variance for all variables that met the 1.0 average load factor rule was above 0.5 . The reliability of the construct analysis was tested using Cronbach's Alpha, which shows that all five summary variable scales were 
between 0.682 and 0.808 , indicating high reliability with the thumb value rule $>$ 0.70 (Taber, 2017). However, according to Bollen (1989), the reliability analysis ( $\alpha=0.682)$ and ( $\alpha=0.674)$ were close to 0.70 so they were considered as acceptable (Karakaya-Ozyer \& Aksu-Dunya, 2018). As a result, the reliability test of AT (0.682) in this research was considered acceptable and reliable. Hence, the overall Divergent Validity measurement was acceptable and reliable.

\subsection{Discriminant Validity Measurement}

Discriminant validity measures the correlations/covariances between factors to measure the degree of differences between the construct/factor and between the overlapping constructs (Hair Jr. et al., 2014) to avoid redundancy in the measurement model (Zainudin, 2012). Discriminating validity is also used to assess the square relationship between two constructs. The primary importance of the Discriminant Validity measurement is that it refers to indicators that do not fit or belong to any variable that cannot be observed or latent (Wang et al., 2015). There are three measures used to evaluate discriminant validity: Cross-Loadings Indicator (Hair Jr. et al., 2014); criterion using a Cross-loading indicator (Fornell \& Larcker, 1981); and Heterotraitmonotrait (HTMT) ratio of correlation (Henseler et al., 2015).

The thumb rule for an acceptable correlation index is less than 0.85 (Taber, 2017) and, the thumb range of square correlation is 0.0 to 1.0 (Hair Jr. et al., 2014). High discriminatory validity implies the uniqueness of constructs that includes concepts not captured by other measures (Hair Jr. et al., 2014). The study adopted the HTMT criterion, as proposed by Henseler, to determine the discriminatory validity test (Henseler et al., 2015). HTMT has a much higher sensitivity and specificity rate of $97 \%$ or $99 \%$. The sensitivity of the HTMT correlation method is $95 \%$ or higher under any simulation conditions to ensure that the measurement model is free of any specific problems (Henseler et al., 2015). The HTMT ratio is also the indicator correlation between variables, thus the geometric mean or hetero-method correlation (Henseler et al., 2015). Since the correlation is an effect size that determines the strength of the correlation, as indicated in Table 7, Evans (1996) suggests an absolute value guide to characterise the strength of a correlation. According to him, the threshold must be $<0.80$.

The validity and reliability of the variables were determined and summarized in Table 7 using the Discriminant Validity Method before structural equation modeling. After completion of the CFA procedure, the outcome of the Discriminant Validity Analysis for this study illustrates that the relationship between all the combined variables was $<0.85$; except for advancement of technology (AT) and User expectation (UE) which had a figure of (0.954). This means that their relationship value of (0.954) implied that the relationship between AT and UE was very high than the accepted rule of thumb less than 0.85 and therefore cannot be accepted. However, Hair Jr. et al. (2010) stated that the value of Discriminant Validity below 1.0 is acceptable. Therefore, since the relationship 
Table 7. Results for discriminant validity measurement.

\begin{tabular}{cccccc}
\hline \multicolumn{7}{c}{ Discriminant Validity Measurement } & & \\
\hline Constructs & $\begin{array}{c}\text { Advancement } \\
\text { of technology }\end{array}$ & $\begin{array}{c}\text { User's } \\
\text { Experience }\end{array}$ & $\begin{array}{c}\text { Competitive } \\
\text { Pressure }\end{array}$ & $\begin{array}{c}\text { Perceived } \\
\text { Ease of Use }\end{array}$ & $\begin{array}{c}\text { Continuous } \\
\text { Digital } \\
\text { Disruption }\end{array}$ \\
\hline $\begin{array}{c}\text { Advancement of } \\
\text { technology (AT) }\end{array}$ & 1.00 & 0.957 & 0.775 & 0.549 & 0.699 \\
User's Experience (UE) & 0.915 & 1.00 & 0.839 & 0.700 & 0.778 \\
Competitive Pressure (CP) & 0.600 & 0.703 & 1.00 & 0.745 & 0.517 \\
Perceived Ease of Use (PU) & 0.301 & 0.490 & 0.555 & 1.00 & 0.642 \\
$\begin{array}{c}\text { Continuous Digital } \\
\text { Disruption (DD) }\end{array}$ & 0.488 & 0.605 & 0.267 & 0.412 & 1.00
\end{tabular}

value of advancement of technology and user expectation valued was (0.957) and the value is below 1.0. It is therefore considered acceptable based on the rule of thumb that Discriminant Validity below 1.0 is acceptable.

On the other hand, the relationship between the other variables fell within the acceptable rule of thumb of $<0.85$; For instance, as shown in yellow on Table 7 . The relationship between AT $-\mathrm{CP}=(0.777) ; \mathrm{AT}-\mathrm{PU}=(0.549) ; \mathrm{AT}-\mathrm{DD}=$ (0.699); $\mathrm{UE}-\mathrm{CP}=0.839 ; \mathrm{UE}-\mathrm{PU}=(0.700) ; \mathrm{UE}-\mathrm{DD}=0.778 ; \mathrm{CP}-\mathrm{PU}=$ $0.745 ; \mathrm{CP}-\mathrm{DD}=(0.517) ; \mathrm{PU}-\mathrm{DD}=(0.642)$, were all within the acceptable rule of thumb $<0.85$. Therefore, their relationship was acceptable and suitable for this analysis. Similarly, the grey colour showed in Table 7 reflects the variables' square correlation factors. For square correlation, the thumb rule states that all variables must be less than 1.0. The square correlation factors for all variables in this study fall within the appropriate range of less than 1.0. For example, $\mathrm{AT}-\mathrm{UE}=(0.915) ; \mathrm{AT}-\mathrm{CP}=(0.600) ; \mathrm{AT}-\mathrm{PU}=(0.301) ; \mathrm{UE}-\mathrm{CP}=$ (0.703); $\mathrm{UE}-\mathrm{PU}=(0.490) ; \mathrm{CP}-\mathrm{PU}=(0.555)$. Therefore, since all of these analysis square correlation figures are within the acceptable thumb rule, the correlation between the various variables was accepted and represents suitability for the study.

\subsection{Structural Equation Modeling}

Structural Equation Modeling (SEM) is a technique that helps to analyse the cause-effect relationship between variables in different fields. SEM is often used to detect a linear correlation between latent and observed variables. These latent variables can be represented by multiple variables observed (Stein et al., 2012). A theoretical model is developed in SEM, showing directional and non-directional correlations between latent and observed variables. SEM is generally used to analyse whether the model is intended to compensate for the variability and covariation of the observed or latent variables (MacCallum \& Austin, 2000). Also, the development of theory and the testing of constructs are two key topics that can be discussed using SEM when the proper experiments are carried out. 
SEM has two main components: a model of measurement and a structural model (Kline, 2005). The measurement model is essentially a confirmatory factor analysis model that confirms whether the data fits the proposed model. The measurement model defines the relationship between latent variables and the different variables observed. The structural model describes the interrelationships between latent variables in the hypotheses of the model. Although SEM was introduced earlier to the education sciences, this method has recently begun to become popular in research (Malaeb et al., 2000) (Figure 8).

The Structural Equation Modeling conceptual framework set out above illustrates the analysis of five variables indicating the impact of advanced technology, competitive pressure, and user expectations on continuous digital disruption using perceive ease of use role as a mediator.

\subsubsection{Validity of Structural Equation Model}

According to Hair Jr. et al. (2012), the validation of the structural model is similar to the Confirmatory Factor Analysis (CFA), but the process calculates a new SEM estimated covariance matrix which is different from the measurement model, and the data observed are still represented by the sample covariance matrix, which should not be modified. The validity of the structural equation model follows the validation of the model of measurement. When an acceptable model

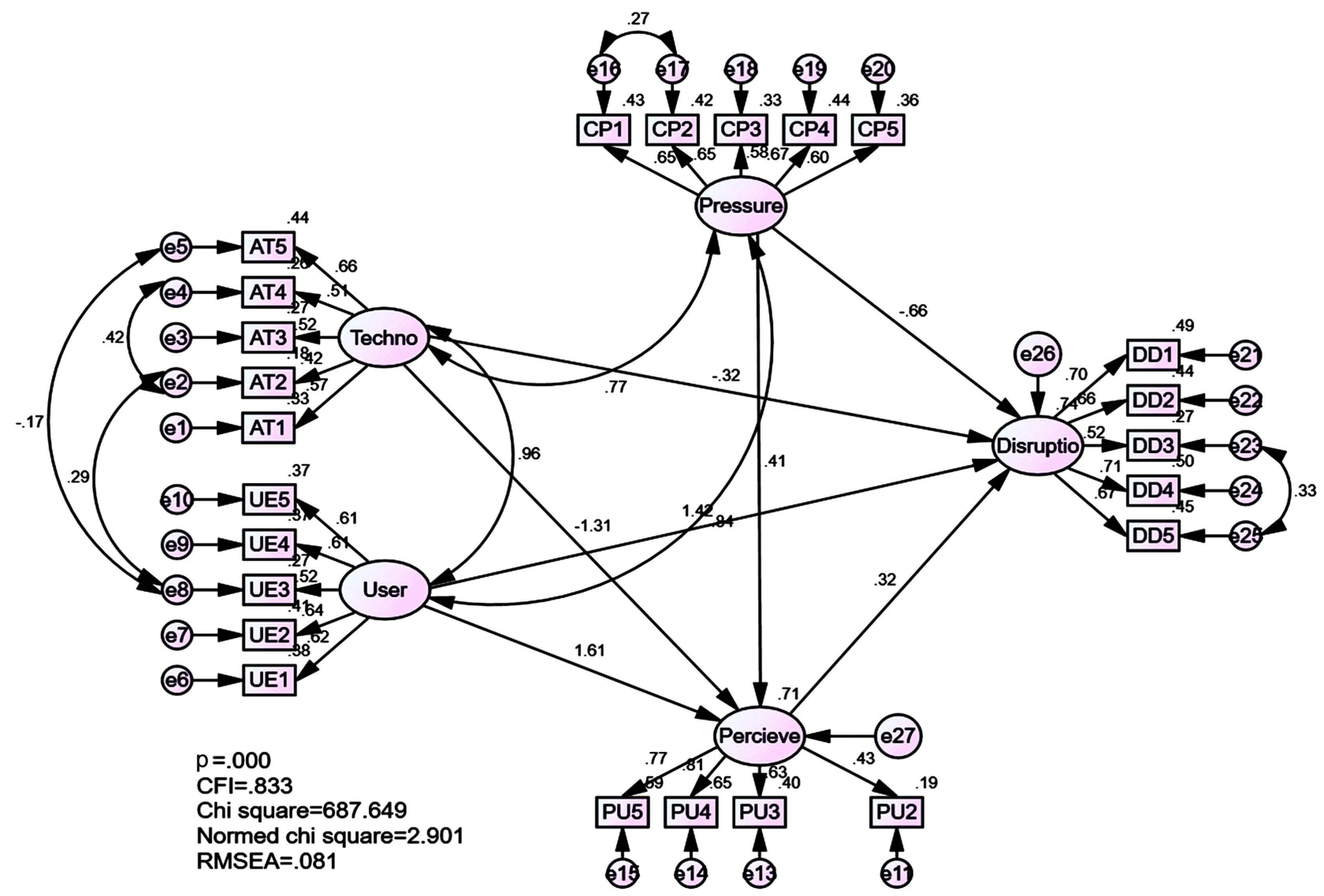

Figure 8. Model: Impact of AT, UE \& CP on DD mediated by PU. 
fit has been achieved and the structural model has been specified, the final stage involves testing the validity of the structural model relationships and their corresponding theoretical hypothesized relationships (Hair Jr. et al., 2012). The overall validity and reliability of the structural model are assessed based on the same parameters as the chi-square, degree of freedom, one for each absolute index, incremental index, goodness-of-fit index, and badness-of-fit index (Hair Jr. et al., 2012).

According to Hair Jr. et al. (2012), a good way to test the validity of SEM is by contrasting the CFA measurement model with the SEM structural model fit since the structural model was generated by a measurement model with additional constraints, if there is an insignificant chi-square check between these two models, it provides empirical evidence for the proposed theoretical model since the results of the loading factors for both models provided the same results in the study (Karakaya-Ozyer \& Aksu-Dunya, 2018). Table 8 shows the validity of the structural equation model and the result shows that the result index for CFA measurements was the same as the result index for the SEM model. This means that the model fits perfectly and that the model was, therefore, suitable for study (Hair Jr. et al., 2012).

Table 8 shows that Chi-Square ( $p$-value) and Normed Chi-square fall within the acceptable range of the structural equation model, with Chi-Square indicating 0.00 below 0.05 and Normed Chi-square indicating 2.901 also less than 3 . Alternatively, with a value of 0.833 , the comparative fit index (CFI) falls slightly below the acceptance level $>0.9$. However, the CFI of 0.833 is justified by another thumb rule, which indicates that the statistical range between 0.0 and 1.0 with a value close to 1.0 implies good fit (Hooper et al., 2008), in which the cut-off criterion is proposed as a thumb rule for CFI 0.90 as a good fit, while CFI $>0.80$ as the lowest criterion for reasonable cut-off values (Bentler \& Bonnet, 1980; Bentler, 1990).

As a result, the CFI value $>0.833$ was accepted based on this thumb rule that the CFI should be $>0.08$. Similarly, the Root Mean Square Approximation Error (RMSEA) was only 0.001 above the 0.08 acceptability level with a value of 0.081 . However, in this analysis, the RMSEA result 0.081 indicates that the model of this study was good because, as mentioned earlier, Hu and Bentler (1999) indicated that RMSEA values ranging from 0 to 1 are good for a model with lower

Table 8. Validity of structural equation model.

\begin{tabular}{cccc}
\hline Name of Index & $\begin{array}{c}\text { Level of } \\
\text { Acceptance }\end{array}$ & $\begin{array}{c}\text { CFA Modified Measurement } \\
\text { Model Result Index }\end{array}$ & $\begin{array}{c}\text { SEM Structural } \\
\text { Model Result Index }\end{array}$ \\
\hline Chi-Square ( $p$-Value) & $<0.05$ & 0.000 & 0.000 \\
Comparative Fit Index (CFI) & $>0.9$ & 0.833 & 0.833 \\
$\begin{array}{c}\text { Root Mean Square Error of } \\
\text { Approximation (RMSEA) }\end{array}$ & $0.03-0.08$ & 0.081 & 0.081 \\
Normed Chi-Square & $<3$ & 2.901 & 2.901 \\
\hline
\end{tabular}


values indicating better fitness. The RMSEA value of 0.081 was therefore considered to be appropriate for the model (Hooper et al., 2008).

\subsubsection{Comparison of Factors Loading}

According to Hair Jr. et al. (2010), proof of the structural model's validity can be seen by comparing loading factors in both the measurement model and the structural model with loading factors $>0.50$ indicating a $100 \%$ similarity to the thumb rule for good model fit. Similarly, the comparison of loading factors between the Measurement Model and the Structural Model in this study shows that all values of both models are perfectly identical, reflecting the good fit of the model because their values are the same. Table 9 below shows that the two models have the same loading factors, indicating a perfect fit for the model.

Table 9. Comparison of factors loading between measurement model and structural model.

\begin{tabular}{|c|c|c|c|}
\hline \multicolumn{4}{|c|}{ Comparison of Factors Loading } \\
\hline & Construct & Modified Measurement Model & Structural Model \\
\hline AT1 & Advancement of Technology & 0.570 & 0.570 \\
\hline AT2 & Advancement of Technology & 0.419 & 0.419 \\
\hline AT3 & Advancement of Technology & 0.522 & 0.522 \\
\hline AT4 & Advancement of Technology & 0.510 & 0.510 \\
\hline AT5 & Advancement of Technology & 0.662 & 0.662 \\
\hline UE1 & User Expectation & 0.615 & 0.615 \\
\hline UE2 & User Expectation & 0.640 & 0.640 \\
\hline UE3 & User Expectation & 0.516 & 0.516 \\
\hline UE4 & User Expectation & 0.610 & 0.610 \\
\hline UE5 & User Expectation & 0.611 & 0.611 \\
\hline $\mathrm{CP} 1$ & Competitive Pressure & 0.654 & 0.654 \\
\hline $\mathrm{CP} 2$ & Competitive Pressure & 0.648 & 0.648 \\
\hline $\mathrm{CP} 3$ & Competitive Pressure & 0.579 & 0.579 \\
\hline $\mathrm{CP} 4$ & Competitive Pressure & 0.666 & 0.666 \\
\hline CP5 & Competitive Pressure & 0.604 & 0.604 \\
\hline PU2 & Perceived Ease of Use & 0.431 & 0.431 \\
\hline PU3 & Perceived Ease of Use & 0.634 & 0.634 \\
\hline PU4 & Perceived Ease of Use & 0.808 & 0.808 \\
\hline PU5 & Perceived Ease of Use & 0.769 & 0.769 \\
\hline DD1 & Continuous Digital Disruption & 0.699 & 0.699 \\
\hline DD2 & Continuous Digital Disruption & 0.663 & 0.663 \\
\hline DD3 & Continuous Digital Disruption & 0.522 & 0.522 \\
\hline DD4 & Continuous Digital Disruption & 0.709 & 0.709 \\
\hline DD5 & Continuous Digital Disruption & 0.672 & 0.672 \\
\hline
\end{tabular}




\subsubsection{Path Analysis Comparison}

Path analysis was used to evaluate the structural relationship by analysing the individual parameter estimates for each specific hypothesis (Hair Jr. et al., 2014) and evaluating the correlation coefficient for calculating the intensity and direction of the causal relationship between two variables (Creswell and Garrett, 2008). The path analysis was also a type of multiple statistical regression analysis used to analyse the relationship between a dependent variable and two or more independent variables to test causal models.

The purpose of the Path Analysis was to assess the causal patterns of variables and the impact or influence of independent variables on dependent variables (Stage et al., 2004). The acceptable range for the correlation coefficient of the structural model was within -1 to +1 . Whereas the correlation coefficient at +1 is a perfectly linear positive of two variables. If the coefficient of correlation is -1 , it means two variables are perfectly related to the negative linear, whereas the coefficient of correlation at zero shows no linear relationship between the two variables (Gogtay \& Thatte, 2017).

The comparison of the path analysis for the measurement model shows a positive relationship between all the variables and the parameter estimates (Table 10). This means that for this study, all the measurement model was within the appropriate range of +1 to -1 ; therefore, there is a positive linear relationship between the variables and the parameter estimates. This indicates a meaningful relationship between the variables. For example, the study shows that advancements of technology (AT), competitive pressure (CP), and user expectations (UE) all have a positive linear relationship with the dependent variable continuous digital disruption (DD). They also have a positive linear relationship with perceive ease of use (PU), and finally perceive ease of use also has a positive linear relation with digital disruption. Specifically, the correlation between AT $\mathrm{DD}=(0.699) ; \mathrm{UE}-\mathrm{DD}=(0.778) ;$ and $\mathrm{UE}-\mathrm{PU}=(0.624)$ figures indicates a higher positive relationship between the variables and the parameter estimates. Additionally, the correlation between $\mathrm{CP}-\mathrm{DD}=(0.517)$; AT $-\mathrm{PU}=(0.549)$;

Table 10. Path analysis comparison.

\begin{tabular}{cccc}
\hline \multicolumn{3}{c}{ Path Analysis Comparison } & \\
\hline \multicolumn{1}{c}{ Measurement Model } & \multicolumn{2}{c}{ Structural Model } \\
\hline Relationship & Parameter Estimates & Impact & Parameter Estimates \\
\hline AT Correlates with DD & 0.699 & AT DD & -0.320 \\
UE Correlates with DD & 0.778 & UEDD & 1.418 \\
CP Correlates with DD & 0.517 & CP DD & -0.665 \\
AT Correlates with PU & 0.549 & AT PU & -1.307 \\
UE Correlates with PU & 0.700 & UEPU & 1.609 \\
CP Correlates with PU & 0.517 & CP PU & 0.408 \\
PU Correlates with DD & 0.642 & PU DD & 0.320 \\
\hline
\end{tabular}


$\mathrm{CP}-\mathrm{PU}=(0.517)$ also indicates a moderate positive relationship between the variables and the parameters estimates.

Contrarily to this, the analysis shows that the structural models have a positive and negative impact on certain variables and parameter estimates. Also, some of the variables are within the acceptable thumb rule of -1 to 1 and the others are beyond the appropriate range of -1 to +1 . The variables that fall within the appropriate range of the thumb rule are $\mathrm{AT}-\mathrm{DD}=(-0.320) ; \mathrm{CP}-\mathrm{DD}=(0.665)$; $\mathrm{CP}-\mathrm{PU}=(0.408)$; and $\mathrm{PU}-\mathrm{DD}=(0.320)$. These figures show that advancement of technology has a negative impact on digital disruption, competitive pressure has a positive impact on digital disruption, competitive pressure has a positive impact on perceived ease of use, and perceived ease of use had a positive impact on digital disruption. Specifically, CP $-\mathrm{DD}=(0.665)$ has a higher positive correlation impact on continuous digital disruption. Also, $\mathrm{CP}-\mathrm{PU}=$ (0.408); and PU - DD = (0.320); has a smaller correlation impact between $\mathrm{CP}-$ PU and PU - DD. Lastly AT - DD $=(-0.320)$; means that there is a insignificant negative correlation impact between advancement of technology (AT) and continuous digital disruption (DD).

Furthermore, variables such as $\mathrm{UE}-\mathrm{DD}=(1.418)$; AT $-\mathrm{PU}=(-1.307)$, UE $\mathrm{PU}=(1.609)$; fell above the acceptable range of -1 to +1 . This means that their estimation of parameters is beyond the acceptable range of -1 to +1 , reflecting an inappropriate range of correlated impact between the constructs and the parameter estimates. Therefore, their values are problematic and unacceptable according to the rule of thumb -1 to -1 .

\subsection{Hypothesis and Mediating Effect Analysis}

The hypotheses test analyses the conclusions of the data samples collected from the target population; the test results show the significance of the conclusion and the probability of the statistics generated from the population hypothesis data (Ly et al., 2015). Hypothesis testing is also a statistical method for drawing decisions using experimental data. The assumption made on the sample of the target population according to Ly et al. (2015) shows the statistical significance of the effect. According to the scholar Hypothesis (H0) is not a nullity or an effect. This shows that the results observed are due to a change in a factor or alternative predictions. Hypothesis (H1) also indicates that the findings are derived from a particular effect (Filho et al., 2013). According to Filho et al. (2013), the test hypothesis represents Estimate, Standard Errors (SE), Critical Ratios (CR), and pvalue $(p)$, the determinant of which the $p$-value is to be accepted or rejected.

Table 11 shows that the findings of the hypothesis test suggest that only competitive pressure was acceptable with a negative estimated impact of $(-0.875)$ on continuous digital disruption and a substantial value or ( $p$-value: $0.015)$ which was within an acceptable range of the rule of thumb $p$-value $<0.05$. The analysis means that the more competitive pressure increases the more continuous digital disruption decreases. According to Howitt \& Cramer (2020), and 
Table 11. Summary of hypothesis and mediating analyses.

\begin{tabular}{|c|c|c|c|c|c|c|c|}
\hline \multicolumn{8}{|c|}{ Model: Impact of AT, UE \& CP on DD Mediated by PU } \\
\hline & & & Estimate & $\begin{array}{c}\text { Standard } \\
\text { Errors (S.E.) }\end{array}$ & $\begin{array}{c}\text { Critical } \\
\text { Ratios (C.R.) }\end{array}$ & $\begin{array}{c}p \text {-Value } \\
(p)\end{array}$ & Result \\
\hline $\begin{array}{c}\text { Perceive } \\
\text { Ease of Use }\end{array}$ & $\leftarrow$ & $\begin{array}{l}\text { Competitive } \\
\text { Pressure }\end{array}$ & 0.364 & 0.351 & 1.037 & 0.300 & $\begin{array}{c}\text { Positive } \\
\text { insignificant }\end{array}$ \\
\hline $\begin{array}{c}\text { Perceive } \\
\text { Ease of Use }\end{array}$ & $\leftarrow$ & $\begin{array}{l}\text { Advancement } \\
\text { of Technology }\end{array}$ & -1.581 & 1.849 & -0.855 & 0.392 & $\begin{array}{c}\text { Negative } \\
\text { insignificant }\end{array}$ \\
\hline $\begin{array}{c}\text { Perceive } \\
\text { Ease of Use }\end{array}$ & $\leftarrow$ & $\begin{array}{c}\text { User } \\
\text { Expectation }\end{array}$ & 1.462 & 1.610 & 0.908 & 0.364 & $\begin{array}{c}\text { Positive } \\
\text { insignificant }\end{array}$ \\
\hline $\begin{array}{c}\text { Digital } \\
\text { Disruption }\end{array}$ & $\leftarrow$ & $\begin{array}{l}\text { Competitive } \\
\text { Pressure }\end{array}$ & -0.875 & 0.360 & -2.428 & 0.015 & $\begin{array}{l}\text { Negative } \\
\text { significant }\end{array}$ \\
\hline $\begin{array}{c}\text { Digital } \\
\text { Disruption }\end{array}$ & $\leftarrow$ & $\begin{array}{l}\text { Advancement } \\
\text { of Technology }\end{array}$ & -0.570 & 2.787 & -0.204 & 0.838 & $\begin{array}{c}\text { Negative } \\
\text { insignificant }\end{array}$ \\
\hline $\begin{array}{c}\text { Digital } \\
\text { Disruption }\end{array}$ & $\leftarrow$ & $\begin{array}{c}\text { User } \\
\text { Expectation }\end{array}$ & 1.897 & 2.546 & 0.745 & 0.456 & $\begin{array}{c}\text { Positive } \\
\text { insignificant }\end{array}$ \\
\hline $\begin{array}{c}\text { Digital } \\
\text { Disruption }\end{array}$ & $\leftarrow$ & $\begin{array}{c}\text { Perceive Ease } \\
\text { of Use }\end{array}$ & 0.472 & 0.645 & 0.732 & 0.464 & $\begin{array}{c}\text { Positive } \\
\text { insignificant }\end{array}$ \\
\hline
\end{tabular}

Demortier (2007), the rule of thumb for accepting a hypothesis, is $p$-value $<0.05$ whereas $p$-value $<0.01$ indicating highly significant (Howitt \& Cramer, 2020). However, all the other variables were found with positive and negative insignificant impact on continuous digital disruption with perceived ease of use $p$-value $>$ 0.05 . Therefore, their hypothesis was rejected because their CR dropped in the crucial region $<1.95$. The critical ratio is linked to the probability of the sample by dividing the mean by the standard deviation to determine the significance of the hypothesis. Also, with 0.05 level of significance, CR shall be $\geq \pm 1.95$ which is the critical region for a two-tailed test for significance hypothesis. Similarly, Massey \& Miller (2019) added that the null hypothesis should be rejected if CR falls in the critical region.

\subsection{Discussion on Findings}

\section{H1: Advancement of technology has a significant impact on continuous digital disruption (Rejected)}

According to Table 11, the impact of advancement of technology on continuous digital disruption estimated value was $(-0.570)$ with significant value or $p$-value of (0.838); higher than the rule of thumb applied in this research which is $p$-value $<(0.05)$; therefore, the proposed hypothesis (H1) was rejected (Hair Jr. et al., 2014). Also, the negative insignificant impact of advancement of technology on continuous digital disruption; means that advancement of technology and digital disruption are not related. Therefore, these research findings indications that advancement of technology has a negative insignificant impact on continuous digital disruption.

The proposed hypothesis was supported by Chui et al. (2016); World Robotics Report (2016); and Avanade Digital (2017), their past research identified ad- 
vancement of technology as having a significant impact on continuous digital disruption. According to Chui et al. (2016), rapid technology advancement growth could automate 45 percent of people's activities which in the long run lead to digital disruption. The World Robotics Report (2016), also forecasted that massive advances in cloud computing, the Internet of Things, data science, robots, drones, cognitive systems, the internet, computer devices, and communications technologies are key determinants of digital disruption. Avanade Digital (2017) revealed that the key drivers of digital disruption are technology innovation. Hence the research proposed that there will be a significant impact of advancement of technology on continuous digital disruption.

However, this study did not support the proposed hypothesis as the findings of the analysis show that there is a negative insignificant impact of advancement of technology on continuous digital disruption. Therefore, the proposed hypothesis was rejected. Nevertheless, these research findings agree with the findings of Davidescu et al. (2020) who found that advancement of technology can diminish employee performance and well-being as flexible time, typically viewed as a benefit of technology providing greater freedom, actually leads to more work hours. Similarly, the research findings of Li (2016) proved that technologies rarely disrupt, but it's how businesses and people in their capacity of consumers, workers, and whatnot leverage. Therefore, their study argued that advancement of technology adoption turns to reduce digital disruption.

H2: Competitive pressure has a significant impact on continuous digital disruption (Accepted)

According to Table 11, the impact of competitive pressure on continuous digital disruption estimated value was $(-0.875)$ with significant value or $p$-value of (0.015); within the acceptable range of the rule of thumb applied in this research which is $p$-value $<(0.05)$; hence, the hypothesis was accepted because the $p$-value of the hypothesis is $<(0.05)$; thou the significant of the impact was negative (Hair Jr. et al., 2014). Also, the negative significant impact of competitive pressure on continuous digital disruption means that the more competitive pressure increases the more digital disruption decrease. Therefore, this research finding indicates that Competitive pressure has a negative significant impact on continuous digital disruption.

The proposed hypothesis was supported by Tech Wire Asia (2018); Ford (2015); and Infosys Limited (2018); their study, indicated that Competitive pressure has a significant impact on continuous digital disruption. Tech Wire Asia (2018) research findings stated that today's digitally transformed environment presents new and unpredictable competitive challenges that companies need to survive and to succeed. According to the researcher, this is because their survey showed that $90 \%$ of firms are facing increased competition from digital companies, either from existing rivals or new entrants. Ford (2015) research findings also established that corporations need to incorporate Artificial Intelligence and robotics to remain competitive, as robots can do research faster and 
cheaper than humans. Infosys Limited (2018) research also concluded that a major driver of digital disruption was market competition (76 percent).

However, the findings of this study confirmed the research findings of other researchers that stated that competitive pressure has a significant negative impact on continued digital disruption. The findings are in line with the research findings of Bughin and Van Zeebroeck (2019), their research findings show that digitization has a significant negative impact on incumbent profits across countries through two-loop effects: digital entrants competing with incumbents through disruptive models, and incumbents responding to disruptions. Furthermore, their research suggests that companies should consider at least two dimensions when designing the kind of bold reactions needed to compete: 1) focusing on new customer segments rather than on current customers alone; and 2) focusing on new ways of re-segmenting the market, rather than relying solely on automation cost-cutting and labour-savings. Although the significant impact was negative, the proposed hypothesis was accepted.

H3: User Expectation has a significant impact on Continuous Digital disruption (Rejected)

According to Table 11, the impact of user expectation on continuous digital disruption was estimated at a value of (1.897) with significant value or $p$-value of (0.456); which is higher than the thumb rule used in this study, which is $p$-value $<(0.05)$; therefore, the hypothesis (H3) was rejected (Hair Jr. et al., 2014). The positive insignificant impact of user expectation on continuous digital disruption means that the more user expectation increases the more digital disruption also increases but the effect of the impact is very low or insignificant. As a result, this research finding rejects the proposed assumption that user expectations have a significant impact on continuous digital disruption.

The proposed hypothesis was supported by Verhoef et al. (2019); Maricar (2014); and Krouskos et al. (2018); in their past research which identified user expectation as having a significant impact on continuous digital disruption. Studies of Verhoef et al. (2019); shown that consumer expectations have a huge effect on continuous digital disruption. Maricar (2014) also found that user expectations in terms of ease of access, ease of payment, complete data, and protection have a positive impact on disruptive innovations. Krouskos et al. (2018) concluded that digital disruption has significantly helped the consumer. The researcher established that the changing needs of end-users are among the main drivers of digital disruption. Their research findings indicated a significant link between user expectations and continuous digital disruption. Hence the study proposed a significant impact of user expectation on continuous digital disruption.

However, this research finding did not support the proposed hypothesis, because the results of this review show that there is a positive insignificant impact of user expectation on continuous digital disruption. This research findings, agree with the research findings of Orsatti and Riemer (2015), whose research findings found that digital disruption often feels sudden yet the source of dis- 
ruption has often been present and even observed for a while before it creates a significant impact because customers' expectations grow with time. Similarly, the research findings of Tornjanski et al. (2017) suggest potential difficulties in implementing new types of banking business models that the digital age places on banks for a large number of consumers of banking services because of user preferences. Also, their study reveals that the main reasons why customers in Serbia do not favour the use of internet-based technologies are that it further facilitates the implementation of new strategies and measures to find effective solutions for both parties. As a result, their research findings indicated an insignificant impact on customers ready for digital disruption.

H4: Advancement of Technology has a significant impact on Perceived Ease of Use (Rejected)

According to Table 11, the impact of advancement of technology on perceive ease of use was estimated at $(-1.581)$ with a substantial value or $p$-value of $(0.392)$ which is higher than the rule of thumb applied in this research, $p$-value $<$ (0.05); therefore, the proposed hypothesis (H4) was rejected (Hair Jr. et al., 2014). The proposed hypothesis was therefore rejected because the $p$-value of the study indicates a negative, insignificant impact of advancement of technology on Perceive ease of use. This means that the more advancement of technology increases the more perceived ease of use decrease but the effect of the impact is very low or insignificant.

The proposed hypothesis was supported by Damerji \& Salimi (2020); Wei et al. (2009); Chong and Yahya (2014); and Gefen and Straub (2000); their past researchers indicated that advancement of technology has a significant impact on perceived ease of use. Damerji \& Salimi (2020) research findings reported that Perceive ease of use is an element of recognition for emerging technologies. Wei et al. (2009) research findings confirmed that the practicality of user-friendly technology will affect the target of initial implementation or continuity of an innovative product, regardless of whether the technology is perceived to be useful. Chong and Yahya (2014) established that perceived ease of use is an intrinsic measure due to constant technological development since it is a major indicator of market acceptance for emerging technologies (Cheong \& Park, 2005; Snowden et al., 2006). Gefen and Straub (2000) concluded that there is a close link between perceived ease of use and technological advances. Based on these findings the study proposed that advancement of technology will have a significant impact on continuous digital disruption.

However, this research analysis did not support the proposed hypothesis, as the findings of the review show that advancement of technology has a negative, insignificant impact on perceive easy to use. Nevertheless, the findings of this study are in line with the research findings of Hoong et al. (2017), and Herzog et al. (2017). The research findings of Hoong et al. (2017), supported Davis' assertion that perceives ease of use does not have a vital effect on behavioural perceptions of the use of digital technologies unless perceive utility or usefulness inter- 
venes in its effects. In the same way, research findings from Vijayasarathy (2004) indicated that perceived ease of use does not have an explicit impact on consumer's behavioural objectives as it affects the perception of the usefulness of behavioural expectations. As a result, their study argued that technological advancement had a negative, insignificant impact on perceived ease of use and a positive significance on perceived usefulness.

H5: Competitive Pressure has a significant impact on Perceived Ease of Use (Rejected)

According to Table 11, the impact of competitive pressure on perceivable ease of use was estimated at a value of (0.364) with a significant value or $p$-value of (0.300); higher than the rule of thumb applied in this research, which is $p$-value $<(0.05)$; therefore, the proposed hypothesis (H5) was rejected (Hair Jr. et al., 2014). Accordingly, the findings of the research show that competitive pressure has a positive insignificant impact on perceived ease of use. This analysis means that the higher the competitive pressure, the higher the perceived ease of use but the impact is very small, negligible, or insignificant. As a result, the research findings rejected the proposed hypothesis that competitive pressure has a significant impact on perceived ease of use.

The proposed hypothesis was supported by Pfeffer and Leblebici (1977); Reich and Benbasat (1990); and Lertwongsatien \& Wongpinunwatana (2003); their past research identified advancement of technology as having a significant impact on perceived ease of use. Pfeffer and Leblebici (1977) research findings revealed that companies are likely to implement innovation in this competitive environment because of intense competition, given that certain rivalry goods are considered more user-friendly than others. Research findings of Reich and Benbasat (1990) reported that an enterprise will allocate resources to deliver new goods or services when the rival company's products are adapted because they are considered easy to use and useful. The researchers also mentioned that most empirical studies have shown that higher opportunities for innovation are correlated with higher competitive pressures due to perceived ease of use of innovative goods. Lertwongsatien \& Wongpinunwatana (2003) research findings found that e-commerce consumers are more likely to adopt new technology in a highly competitive market because they find it convenient to use. These research findings indicated a significant link between competitive pressure and perceive ease of use. Hence this research assumed a significant impact of competitive pressure and perceive ease of use

However, the findings of this study did not support the proposed hypothesis, as the findings of this analysis show that there is an insignificant positive impact of competitive pressure on perceived ease of use. These findings are consistent with the findings of Al-Fahim et al. (2016); Arvidsson (2014); and Kim et al. (2010). Al-Fahim et al. (2016) research findings reported that competitive pressure had an insignificant impact on perceived ease of use, as the three main issues related to perceived ease of use are easy to manage, easy to use, and easy to 
learn in Omani banks. Research results from Arvidsson (2014) revealed that ease of use, trust, and perceived security is critical in predicting the adoption of mobile payment services, and not competitive pressure. Kim et al. (2010) also found that competitive pressure is of insignificant value when it comes to the perception of ease of use as convenience, interactivity, compatibility, and expected effort was the significant predictor in location-based service adoption in the retail environment. Hence, their study argued that competitive pressure had an insignificant impact on perceived ease of use.

H6: User Expectation has a significant impact on Perceived Ease of Use (Rejected)

According to Table 11, the effect of user expectation on perceived ease of use was estimated at a value of (1.462) with a substantial value or $p$-value of $(0.364)$ higher than the rule of thumb used in this research, which is $p$-value $<(0,05)$; hence hypothesis (H6) was rejected (Hair Jr. et al., 2014). The positive, insignificant impact of user expectations on perceive ease of use means that the higher user expectations, the more perceived ease of use increases, but the impact is very low or insignificant. Hence, these research findings refute the suggested hypothesis that user expectations have a significant impact on perceive ease of use.

The proposed hypothesis was supported with Hubert et al. (2018); Mouakket (2009); Davis (1989); Ke et al. (2012); Joo and Kim (2017); Oghuma et al. (2016); Thong et al. (2006); and Kim et al. (2010). Their past research identified user expectations as having a significant impact on perceived ease of use. According to the scholars, user expectations may be influenced by the ease of use of technology and indirectly influence user intention to implement it. Furthermore, previous studies show that perceive ease of use affects the perceived value or intent of increasing smartphone users (Hubert et al., 2018). Davis (1989), in his research findings stated a constructive relationship between perceive ease of use and consumer expectations. Ke et al. (2012), research findings suggest that the impact of user behaviour on perceived ease of use is greater than that of system characteristics, and if adequate user acceptance testing is carried out early on in the design, the likelihood of user rejection could be minimized and preventive and predictive measures could be applied to ensure potential user acceptance. Scholars also reported in digital environments that user expectations have a beneficial impact on the ease of use of digital products (Joo \& Kim, 2017; Oghuma et al., 2016). Oghuma et al. (2016) studies confirmed a positive relationship between clarity and perception of ease of use or expectation and ease of use (Thong et al., 2006). Similarly, Kim et al. (2010) stressed that, if the wishes of consumers are met with initial experience, they are likely to use these services to maintain a cognitive balance. Likewise, Joo and Kim's (2017) research findings concluded that user expectations have a significant correlation with perceived ease of use. Thus, their findings suggest a major link between user expectations and perceive ease of use. Therefore, the study assumed that there will be a sig- 
nificant impact of user expectations on perceived ease of use.

Nevertheless, this present research study did not endorse the proposed hypothesis, as the review results indicate that there is a positive insignificant impact of user expectation on continuous digital disruption. All the same, these research findings agree with the findings of numerous studies (Hong et al., 2006; Liao et al., 2007; Almarashdeh, 2014). Amin et al. (2014) and Baki et al. (2018), research findings confirmed that perceive ease of use is influenced by user expectations. According to Hong et al. (2006), if the interaction tool (i.e. website or apps) is not user-friendly, easy to use, or effortless, the behaviours of consumers during the online shopping process may be negatively affected. Almarashdeh (2014), research findings stated that previous research has shown that user expectation and satisfaction is an important factor affecting the continued usage intentions in knowledge sharing. This research finding is also in agreement with Amin et al. (2014) and Baki et al. (2018), who reported that users show higher degrees of satisfaction for perceived usefulness relative to perceived ease of use. Therefore, their study argued that User expectation has a positive insignificant impact on perceived ease of use.

H7: Perceive Ease of Use has a significant impact on Continuous digital disruption. (Rejected)

According to Table 11, the impact of perceive ease of use on continuous digital disruption was estimated at a value of (0.472) with a significant value or $p$-value of (0.464) higher than the thumb rule applied in this research, which is $p$-value < (0.05); Hence hypothesis (H7) was rejected (Hair Jr. et al., 2014). The positive insignificant impact of perceived ease of use on digital disruption suggests that the more perceived ease of use increases, the more digital disruption also increases, but the impact is very small or insignificant. Because of that, the results of this research rejected the suggested hypothesis that there is a significant impact of perceive ease of use on continuous digital disruption.

The proposed hypothesis was supported by Venkatesh and Davis (2000); Alsabawy et al. (2016); Gefen and Straub (2000) and Bettayeb et al. (2020); their past research identified perceive ease of use as having a significant impact on continuous digital disruption. According to Venkatesh and Davis (2000), perceived ease of use is a key driver of digital disruption, technology acceptance, adoption, and use. Alsabawy et al. (2016), similarly, found that the main determinants of digital disruption were the general perception of the individual's ease of use concerning computers. Pew Research Center (2017) current work also called on practitioners to develop and implement general computer skills training programs as they have a strong impact on the acceptance and continued use of new systems that causes continuous digital disruption. Based on these research findings, the study proposed a significant impact of perceive ease of use on digital disruption.

However, this study did not support the proposed hypothesis, as the findings of this research analysis show that perceived ease of use has a positive negligible 
impact on continuous digital disruption. At the same time, these research findings are consistent with the findings of (Kirschner \& Karpinski, 2010; Junco and Cotten 2012). Kirschner \& Karpinski (2010) argued that a detrimental effect on success would result from involvement or dependence on digital technology due to ease of use. Junco and Cotten (2012) analysed the relationship between different Facebook frequency measures and time spent preparing for classes and overall GPAs, and his findings suggest that time spent on Facebook or students using digital technology was strongly and significantly negatively associated with the overall GPA. Therefore, their study argued that perceive ease of use has a positive insignificant impact on digital disruption.

H8: Perceived ease of use as a mediator on the relationship between Advancement technology, Competition pressure, User expectation, and Continuous digital disruption.

The objective of the mediation model in the research analysis was to identify and explain the mechanism or process that underlies the observed relationship between the independent variable and the dependent variable by including a third hypothetical variable, known as the mediator variable. The mediator variable thus helps to explain the essence of the relationship between the independent variable and the dependent variable. Mediation research facilitates a deeper understanding of the relationship between independent and dependent variables when there seems to be no clear correlation between variables.

In this research, the SmartPLS model was used to analyse the mediation relationship between the independent and dependent variables. Thus, the SmartPLS model was used in this study to examine the relationship between perceived ease of use as a mediator and the relationship between advancement of technology, competitive pressure, user expectations, and continuous digital disruption. These research findings showed that there is a negative, insignificant impact between advancement of technology and continuous digital disruption, a positive, insignificant impact between user expectations and continuous digital disruption, and a negative significant impact between competitive pressure and continuous digital disruption. Similarly, there was a negative insignificant impact between advancement of technology and perceived ease of use. Competitive pressure and perceived ease of use also showed a positive insignificant impact. User expectation and perceived ease of use showed a positive insignificant impact and Perceive ease of use and continuous digital disruption indicated a positive insignificant impact.

In summary, the overall result shows an insignificant relationship between the mediator and the independent and dependent variable, except for the relationship between competitive pressure and continuous digital disruption, which showed a significant negative relationship. Similarly, the relationship between the mediator (perceive ease of use) and all variables were insignificant. Therefore, based on this study, the mediator and the variables have no mediation impact or significant impact because the result indicates that there is no meaningful interaction between the mediator and the variable. However, as mentioned 
earlier past researches reported an insignificant impact between advancement of technology and continuous digital disruption ( $\mathrm{Li}, 2016)$. A negative relationship was reported between competitive pressure and continuous digital disruption (Bughin and Zeebroeck, 2017). Previous findings also showed a positive insignificant impact between User expectation and continuous digital disruption (Orsatti and Riemer, 2015; Tornjanski et al., 2017, Aly, 2020). The research findings of (Hoong et al., 2017; Elkaseh et al., 2016) indicated an insignificant impact between advancement of technology and continuous digital disruption. Abdekhoda et al. (2016) reported a negative significant impact between competitive pressure and perceive ease of use. Liao et al. (2007) and Galib et al. (2018); research findings reported an insignificant positive impact between user expectations and perceive ease of use. Kirschner and Karpinski (2010) research findings stated an insignificant positive impact between perceived ease of use and continuous digital disruption. However, the review of this study shows no mediating impact. This means that there was no significant relationship between the mediator and the variables. Therefore, the hypothesis (H8) was rejected.

\section{Conclusion and Recommendation}

This research finding did not support previous studies that established a positive relationship between advancement of technology, competitive pressure, and user expectations on continuous digital disruption. However, the research was consistent with studies that suggest that there is no significant impact on continuous digital disruption with technological advancement and user expectations. The study further confirms findings of previous studies that found competitive pressure to be negatively related to digital disruption. Comparably, perceived ease of use as a mediator showed to be insignificant or to have no mediating effect on the various variables. The study, therefore, recommends that future studies can use the same variable, but the sample size for the research should be limited to a single organization or institution. Future research can also extend over different periods to examine theoretical models and conceptual frameworks using a longitudinal validation approach, which could be more valuable in refining the proposed model. Future studies may also use a qualitative approach or a combination of quantitative and qualitative methodology rather than the quantitative approach used in this study. The present study used a small sample size of 292, future studies should use a larger sample size. This analysis used the non-probability sampling methodology. Future studies can use the probability sampling approach to provide relatively reliable results by reducing the margin of error for further research. Finally, future studies can also use other independent variables to determine their impact on continuous digital disruption rather than advancement of technology, competitive pressure, and user expectations.

\section{Acknowledgements}

First and foremost, I give praises and thanks to the Almighty God for His bless- 
ings and protection throughout this research. Additionally, I would like to express my deep and sincere gratitude to my supervisor Mr. Abdul Basit of IUMW Business School (IBS), for providing me with an invaluable guideline throughout my research. His dynamism and motivation deeply inspired me throughout this study. He guided me through the methodology and in presenting my work as clearly as possible. It was a great privilege and honour to work and study under his guidance. Similarly, I am extending my heartfelt thanks to all lecturers and staff of IUMW Business School (IBS) for teaching and providing me with the necessary support during my postgraduate studies.

Furthermore, I am extremely grateful to my Parents Mr. Kwasi Addei Addison and Mrs. Felicia Addison for their love, prayers, and sacrifices in taking care of my daughter Maame Nhyira Addison while I pursued my MBA abroad. Also, I would like to say a big thank you to my siblings Doreen, Eric and Lydia for their advice and comments throughout the process. Lastly, special thanks go to all my friends and families who in one way or the other contributed to the completion of this thesis.

\section{Dedication}

This thesis is dedicated; to my beloved daughter Maame Nhyira Addison, whose presence in my life is without a doubt a blessing and a motivator for me to strive for greater heights.

\section{Conflicts of Interest}

The author declares no conflicts of interest regarding the publication of this paper.

\section{References}

Abdekhoda, M., Ahmadi, M., Dehnad, A., Noruzi, A., \& Gohari, M. (2016). Applying Electronic Medical Records in Health Care: Physicians' Perspective. Applied Clinical Informatics, 7, 241-354. https://doi.org/10.4338/ACI-2015-11-RA-0165

Adeniji C. et al. (2018). Data on the Impact of Technological Change on Employees' Cognitive Attitude and Organizational Performance. Data in Brief, 18, 1360-1364.

Ahad, N. A., Teh, S. Y., Othman, A. R., \& Yaakob, C. R. (2011). Sensitivity of Normality Tests to Non-Normal Data. Saints Malaysian, 40, 637-641.

Akhtar, I. (2016). Research Design. In Research in Social Science: Interdisciplinary Perspectives (p. 17)

Al-Fahim, N. H., Wan Jusoh, W. J., \& Adewale, A. A. (2016). An Examination Factors Influencing the Intention to Adopt Internet Banking among SMES in Yemen: Using an Extension of the Technology Acceptance Model (TAM). Journal of Internet Banking and Commerce, 21, 1-23.

Al-Gahtani, S. (2001). The Applicability of TAM outside North America: An Empirical Test in the United Kingdom. Information Resources Management Journal (IRMJ), 14, 37-46. https://doi.org/10.4018/irmj.2001070104

Almalki, S. (2016). Integrating Quantitative and Qualitative Data in Mixed Methods Re- 
search-Challenges and Benefits. Journal of Education and Learning, 5, 288-296. https://doi.org/10.5539/jel.v5n3p288

Almarashdeh, I. (2014). An Overview of Technology Evolution: Investigating the Factors Influencing Non-Bitcoins Users to Adopt Bitcoins as Online Payment Transaction Method. Journal of Theoretical and Applied Information Technology, 96, 3984-3993.

Alsabawy, A. Y., Cater-Steel, A., \& Soar, J. (2016). Determinants of Perceived Usefulness of E-Learning Systems. Computers in Human Behaviour, 64, 843-858. https://doi.org/10.1016/j.chb.2016.07.065

Alsamydai, M. J. (2014). Adaptation of the Technology Acceptance Model (TAM) to the Use of Mobile Banking Services. International Review of Management and Business Research, 3, 2039-2051.

Aly, H. (2020). Digital Transformation, Development and Productivity in Developing Countries: Is Artificial Intelligence a Curse or a Blessing? Review of Economics and Political Science, ahead-of-print. https://doi.org/10.1108/REPS-11-2019-0145

Amin, M., Rezaei, S., \& Abolghasemi, M. (2014). User Satisfaction with Mobile Websites: The Impact of Perceived Usefulness (PU), Perceived Ease of Use (PEOU) and Trust. Nankai Business Review Intentional, 5, 258-274. https://doi.org/10.1108/NBRI-01-2014-0005

Arbuckle, J. L. (2013). IBM SPSS Amos ${ }^{\text {TM }} 22$ User's Guide.

Arthur, W. B. (2009). The Nature of Technology: What It Is and How It Evolves.

Arvidsson, N. (2014). Consumer Attitudes on Mobile Payment Services-Results from a Proof of Concept Test. International Journal of Bank Marketing, 32, 150-170. https://doi.org/10.1108/IJBM-05-2013-0048

Ary, D., Jacobs, L., \& Razavieh, A. (2002). Introduction to Research (6th ed.). Wadsworth. Avanade Digital (2017). Cashing in on Digital Disruption: How to Keep Up in the Banking Sector (p. 11). Avanade Inc.

Awa, H. O., Ukoha, O., \& Igwe, S. R. (2017). Revisiting Technology-Organization-Environment (T-O-E) Theory for Enriched Applicability. Bottom Line, 30, 2-22. https://doi.org/10.1108/BL-12-2016-0044

Bain, R. (1937). Technology and State Government. American Sociological Review, 2, 860 874. https://doi.org/10.2307/2084365

Baki, R., Birgoren, B., \& Aktepe, A. (2018). A Meta-Analysis of Factors Affecting Perceived Usefulness and Perceived Ease of Use in the Adoption of E-Learning Systems. Turkish Online Journal of Distance Education, 19, 4-42.

Barbour, I. G. (2014). Ethics in an Age of Technology (312 p). Harper.

Barrett, P. (2007). Structural Equation Modeling: Adjudging Model Fit. Personality and Individual Differences, 42, 815-824. https://doi.org/10.1016/j.paid.2006.09.018

Bartlett, J. E., Kotrlik, J. W., \& Higgins, C. C. (2001). Organizational Research: Determining Appropriate Sample Size in Survey Research. Information Technology, Learning, and Performance Journal, 19, 43-50.

Beauducel, A., \& Wittmann, W. (2005). Simulation Study on Fit Indexes in CFA Based on Data with Slightly Distorted Simple Structure. Structural Equation Modeling, 12, 41-75. https://doi.org/10.1207/s15328007sem1201 3

Bentler, M. (1990). Comparative Fit Indexes in Structural Models. Psychological Bulletin, 107, 238-246. https://doi.org/10.1037/0033-2909.107.2.238

Bentler, M., \& Bonett, G. (1980). Significance Tests and Goodness of Fit in the Analysis of Covariance Structures. Psychological Bulletin, 88, 588-606. 
https://doi.org/10.1037/0033-2909.88.3.588

Bernard, A., Jensenc, J. B., \& Schott, P. K. (2006). Survival of the Best Fit: Exposure to Low-Wage Countries and the (Uneven) Growth of U.S. Manufacturing Plants. Journal of International Economics, Elsevier, 68, 219-237.

https://doi.org/10.1016/j.jinteco.2005.06.002

Bertrand, M., \& Bouchard, S. (2008). Applying the Technology Acceptance Model to VR with People Who Are Favourable to Its Use. Journal of Cyber Therapy and Rehabilitation, 1, 200-207.

Bettayeb, H., Turki Alshurideh, M., \& Al Kurdi, B. (2020). The Effectiveness of Mobile Learning in UAE Universities: A Systematic Review of Motivation, Self-Efficacy, Usability and Usefulness. International Journal of Control and Automation, 13, 1558-1579.

Bharadwaj, A., El Sawy, O. A., Pavlou, P. A., \& Venkatraman, N. (2013). Digital Business Strategy: Toward a Next Generation of Insights. MIS Quarterly: Management Information Systems, 37, 471-482. https://doi.org/10.25300/MISQ/2013/37:2.3

Blanche, M. T., Durrheim, K., \& Painter, D. (2006). Research in Practice: Applied Methods for Social Sciences (2nd ed.). UCT Press.

Bollen, A. (1989). Structural Equations with Latent Variables (528 p). John Wiley and Sons, Inc. https://doi.org/10.1002/9781118619179

Brannmark, J., \& Sahlin, N. E. (2010). Ethical Theory and the Philosophy of Risk: First Thoughts. Journal of Risk Research, 13, 149-161.

https://doi.org/10.1080/13669870903126192

Brown, T. A. (2006). Confirmatory Factor Analysis for Applied Research. The Guilford Press.

Bruijl, G. (2018). The Relevance of Porter's Five Forces in Today's Innovative and Changing Business Environment. SSRN Electronic Journal. https://doi.org/10.2139/ssrn.3192207

Bruque, S., \& Moyano, J. (2007). Organisational Determinants of Information Technology Adoption and Implementation in SMEs: The Case of Family and Cooperative Firms. Technovation, 27, 241-253. https://doi.org/10.1016/j.technovation.2006.12.003

Bughin, J., \& Van Zeebroeck, N. (2017). The Best Response to Digital Disruption. MIT Sloan Management Review, 58, 80-86. https://doi.org/10.5465/AMBPP.2017.15155abstract

Bughin, J., \& Van Zeebroeck, N. (2019). The Best Response to Digital Disruption: Companies That Adopt Bold Strategies in the Face of Industry Digitization Improve Their Odds of Coming Out Winners. Journal of Management Information Systems, 18, 97-124.

Bughin, J., Hazan, E., Ramaswamy, S., Allas, T., Dahlstrom, P., Henke, N., \& Trench, M. (2017). Artificial Intelligence: The Next Digital Frontier? McKinsey Global Institute.

Bumann, J., \& Peter, M. K. (2016). Action Fields of Digital Transformation-A Review and Comparative Analysis of Digital Transformation Maturity Models and Frameworks.

Burrell, G., \& Morgan, G. (2019). Sociological Paradigms and Organisational Analysis. Routledge. https://doi.org/10.4324/9781315609751

Campbell, D. T., \& Fiske, D. W. (1959). Convergent and Discriminant Validation by the Multitrait-Multimethod Matrix. Psychological Bulletin, 56, 81-105. https://doi.org/10.1037/h0046016

Caruana, E. J., Roman, M., Hernández-Sánchez, J., \& Solli, P. (2020). Longitudinal Studies. Journal of Thoracic Disease, 7, E537-E540.

Cascio, W. F., \& Montealegre, R. (2016). How Technology Is Changing Work and Or- 
ganizations. Annual Review of Organizational Psychology and Organizational Behaviour, 3, 349-375. https://doi.org/10.1146/annurev-orgpsych-041015-062352

Chartered Accountants Australia \& New Zealand (2015). The Future of Block Chain: Applications and Implications of Distributed Ledger Technology. Future Inc.

Cheong, H. J., \& Park, M. C. (2005). Mobile Internet Acceptance in Korea. Internet Research, 15, 125-140. https://doi.org/10.1108/10662240510590324

Chong, A., \& Yahya, F. B. (2014). State, Society and Information Technology in Asia (248 p). Routledge Taylor \& Francis Ltd.

Christensen, C. M. (1997). The Innovator's Dilemma: When New Technologies Cause Great Firms to Fail. Harvard Business School Press.

Christensen, C. M., \& Raynor, M. E. (2003). Book Excerpt-The Innovator's SolutionWhat Customers Really Want Is for You to Do Their Jobs. CIO.

Christensen, C. M., McDonald, R., Altman, E. J., \& Palmer, J. E. (2018). Disruptive Innovation: An Intellectual History and Directions for Future Research. Journal of Management Studies, 55, 1043-1078. https://doi.org/10.1111/joms.12349

Christensen, C. M., Raynor, M. E., \& McDonald, R. (2015). What Is Disruptive Innovation? pp. 44-53) of Harvard Business Review.

Chui, M., Manyika, J., \& Miremadi, M. (2016). Where Machines Could Replace Humans-And Where They Can't (Yet). McKinsey.

Creswell, J. W., \& Garrett, A. L. (2008). The "Movement" of Mixed Methods Research and the Role of Educators. South African Journal of Education, 28, 321-333.

https://doi.org/10.15700/saje.v28n3a176

Dahlman, C. (2018). Technology, Globalization and International Competitiveness: Challenges for Developing Countries. In Industrial Development for the 21st Century (pp. 29-83). United Nations.

Damerji, H., \& Salimi, A. (2020). Mediating Effect of Use Perceptions on Technology Readiness and Adoption of Artificial Intelligence in Accounting. Accounting Education, 30, 107-130. https://doi.org/10.1080/09639284.2021.1872035

Davidescu, A. A. M., Apostu, S.-A., Paul, A., \& Casuneanu, I. (2020). Work Flexibility, Job Satisfaction, and Job Performance among Romanian Employees-Implications for Sustainable Human Resource Management. Sustainability.

Davis, F. D. (1986). A Technology Acceptance Model for Empirically Testing New EndUser Information Systems: Theory and Results. Sloan School of Management, Massachusetts Institute of Technology.

Davis, F. D. (1989). Perceived Usefulness, Perceived Ease of Use, and User Acceptance of Information Technology. MIS Quarterly, 13, 319-340. https://doi.org/10.2307/249008

Davis, F. D. (1993). User Acceptance of Information Technology: System Characteristics, User Perceptions and Behavioural Impacts. International Journal of Man-Machine Studies, 38, 475-487. https://doi.org/10.1006/imms.1993.1022

Deloitte (2018). 2018 Deloitte Global Automotive Consumer Study Module 2: Advanced Technology Update \& Customer Experience. Primary Insights.

Demortier, L. (2007). P Values and Nuisance Parameters. In L. Lyons, H. Prosper, \& A. de Roeck (Eds.) PHYSTAT-LHC Workshop on Statistical Issues for LHC Physics (pp. 23-33). CERN.

Devanandan, K. V., \& Lakshmi, R. (2018). ICT Embedded Education and Research: A Hand Guide for Teachers and Researchers. Notion Press, Inc.

Dhurup, M., \& Dlodlo, N. (2013). Drivers of E-Marketing Adoption among Small and 
Medium Enterprises (SMEs) and Variations with Age of Business Owners (Vol. 336). Oxford University Press.

Dobbs, R., Manyika, J., \& Woetzel, J. (2018). No Ordinary Disruption: The Four Global Forces Breaking All the Trends. McKinsey Global Institute, McKinsey \& Company.

Dohan, M. S., \& Tan, J. (2013). Perceived Usefulness and Behavioural Intention to Use Consumer-Oriented Web-Based Health Tools: A Meta-Analysis.

Ducey, J., \& Coovert, M. D. (2013). Predicting Tablet Computer Use: An Extended Technology Acceptance Model. Health Policy and Technology, 5, 268-284. https://doi.org/10.1016/j.hlpt.2016.03.010

Elbanna, A., \& Newman, M. (2016). Disrupt the Disruptor: Rethinking "Disruption" in Digital Innovation. In Proceeding of the 10th Mediterranean Conference on Information Systems Paphos (pp. 58-71). Association for Information Systems, AIS Electronic Library (AISeL)

Elkaseh, A. M., Wong, K. W., \& Fung, C. C. (2016). Perceived Ease of Use and Perceived Usefulness of Social Media for e-Learning in Libyan Higher Education: A Structural Equation Modeling Analysis. International Journal of Information and Education Technology, 6, 192-199. https://doi.org/10.7763/IJIET.2016.V6.683

Evans, R. H. (1996). An Analysis of Criterion Variable Reliability in Conjoint Analysis. Perceptual and Motor Skills, 84, 988-990. https://doi.org/10.2466/pms.1996.82.3.988

Fairlie, W., \& Fossen, M. (2018). Opportunity versus Necessity Entrepreneurship: Two Components of Business Creation. SOE Ppaper No. 959.

https://doi.org/10.2139/ssrn.3169864

Farmer, G. D., Warren, P. A., El-Deredy, W., \& Howes, A. (2016). The Effect of Expected Value on Attraction Effect Preference Reversals. Journal of Behavioural Decision Making, 30, 785-793. https://doi.org/10.1002/bdm.2001

Filho, D. B. F., Paranhos, R., da Rocha, E. C., Batista, M., da Silva Jr., J. A., Santos, M. L. W. D., \& Marino, J. G. (2013). When Is Statistical Significance Not Significant? Brazilian Political Science Review, 7, 31-55. https://doi.org/10.1590/S1981-38212013000100002

Fisher, J. C., \& Pry, R. H. (1971). A Simple Substitution Model of Technological Change. Technological Forecasting and Social Change, 3, 75-88. https://doi.org/10.1016/S0040-1625(71)80005-7

Forbes (2020). Customer Service Expectations Are Rising-Is Your Business Keeping Up? Forbes.

Ford, M. (2015). Rise of the Robots: Technology and the Threat of a Jobless Future. Basic Books.

Fornell, C., \& Larcker, F. (1981). Structural Equation Models with Unobservable Variables. Journal of Marketing Research, 18, 382-388. https://doi.org/10.1177/002224378101800313

Fossen, F., \& Sorgner, A. (2018). The Effects of Digitalization on Employment and Entrepreneurship. Semantic Scholar.

Frésard, L., \& Valta, P. (2012). Competitive Pressure and Corporate Investment: Evidence from Trade Liberalization. SSRN Electronic Journal.

https://doi.org/10.2139/ssrn.2023029

Galib, M. H., Hammou, K. A., \& Steiger, J. (2018). Predicting Consumer Behaviour: An Extension of Technology Acceptance Model. International Journal of Marketing Studies, 10, 73-90. https://doi.org/10.5539/ijms.v10n3p73 
Ganguly, A. et al. (2010). Defining a Set of Metrics to Evaluate the Potential Disruptiveness of a Technology. Engineering Management Journal, 22, 34-44. https://doi.org/10.1080/10429247.2010.11431851

Gartner Glossary (2016). Willful Disruption: Scaling, Operating and Changing the Digital Game. Gartner Research.

Gartner Glossary (2018). Information Technology (IT) Glossary-Essential Information Technology (IT) Terms \& Definitions. Gartner.

Gartner Glossary (2020). Definition of Digital Disruption-IT Glossary. Gartner. Information Technology Gartner Glossary.

Gefen, D., \& Straub, D. (2000). The Relative Importance of Perceived Ease of Use in IS Adoption: A Study of E-Commerce Adoption. Journal of the Association for Information Systems, 1, Article 8. https://doi.org/10.17705/1jais.00008

Genesys (2020). The Secrets to Customer Experience Success in 2020 and Beyond. Genesys.

George, D., \& Mallery, P. (2010). SPSS for Windows Step by Step: A Simple Guide and Reference. 17.0 Update-Ghent University Library.

Ghasemi, A., \& Zahediasl, S. (2012). Normality Tests for Statistical Analysis: A Guide for Non-Statisticians. International Journal of Endocrinology and Metabolism, 10, 486-489. https://doi.org/10.5812/ijem.3505

Gimpel, H., Hosseini, S., Huber, R., Probst, L., Roglinger, M., \& Faisst, U. (2018). Structuring Digital Transformation: A Framework of Action Fields and Its Application at ZEISS. Journal of Information Technology Theory and Application, 19, 31-54.

Glasow, P. (2005). Fundamentals of Survey Research Methodology. MITRE, C3 Center.

Gobble, M. A. M. (2018). Digital Strategy and Digital Transformation. Research Technology Management, 61, 66-71. https://doi.org/10.1080/08956308.2018.1495969

Gogtay, N. J., \& Thatte, U. M. (2017). Principles of Correlation Analysis. The Journal of the Association of Physicians of India, 65, 78-81.

Gravetter, F., \& Wallnau, L. (2014). Essentials of Statistics for the Behavioral Sciences (8th ed.). Wadsworth.

Greenwood, B. N., \& Wattal, S. (2017). Show Me the Way to Go Home: An Empirical Investigation of Ride-Sharing and Alcohol-Related Motor Vehicle Fatalities. MIS Quarterly, 41, 163-187. https://doi.org/10.25300/MISQ/2017/41.1.08

Greeven, M., Yu, H., \& Shan, J. (2018). Why Companies Must Embrace Microservices and Modular Thinking. MIT Sloan Management Review.

Greif, H., \& Garfinkel, H. (2016). Digital Transformation and FinTechs: How Innovation Changes the Financial Services Industry.

Hair Jr., J. F., Black, W. C., Babin, B. J., \& Anderson, R. E. (2010). Multivariate Data Analysis: A Global Perspective (7th ed.). Pearson Education.

Hair Jr., J. F., Black, W. C., Babin, B. J., Anderson, R. E., \& Tatham, R. L. (2006). Multivariate Data Analysis (Vol. 6). Pearson Prentice Hall.

Hair Jr., J. F., Ringle, C. M., \& Sarstedt, M. (2012). Partial Least Squares: The Better Approach to Structural Equation Modeling? Long Range Planning, 45, 312-319. https://doi.org/10.1016/j.lrp.2012.09.011

Hair Jr., J. F., Sarstedt, M., Hopkins, L., \& Kuppelwieser, V. G. (2014). Partial Least Squares Structural Equation Modeling (PLS-SEM): An Emerging Tool in Business Research. European Business Review, 26, 106-121.

https://doi.org/10.1108/EBR-10-2013-0128 
Harding, L. K. et al. (2015). Electron Multiplication CCD Detector Technology Advancement for the WFIRST-AFTA Coronagraph. Proceedings of SPIE, 9605, 96050F.

Hauser, P. M., \& Duncan, O. D. (1972). The Study of Population: An Inventory and Appraisal. University of Chicago Press.

Henseler, J., Ringle, C. M., \& Sarstedt, M. (2015). A New Criterion for Assessing Discriminant Validity in Variance-Based Structural Equation Modeling. Journal of the Academy of Marketing Science, 43, 115-135. https://doi.org/10.1007/s11747-014-0403-8

Herzog, M. et al. (2017). 10 Principles for Winning the Game of Digital Disruption. Tech \& Innovation.

Hill, J. (2017). Spotting and Responding to Digital Disruption Leading through Digital Disruption. Distinguished Gartner Insights.

Holzer, H. (2018). Better Skills for Better Jobs. Issues in Science and Technology, 28.

Hong, S. J., Thong, J. Y. L., \& Tam, K. Y. (2006). Understanding Continued Information Technology Usage Behaviour: A Comparison of Three Models in the Context of Mobile Internet. Decision Support Systems, 42, 1819-1834.

https://doi.org/10.1016/j.dss.2006.03.009

Hoong, A. L. S., Thi, L. S., \& Lin, M.-H. (2017). Affective Technology Acceptance Model: Extending Technology Acceptance Model with Positive and Negative Affect. In M. Mohiuddin, N. Halilem, S. M. A. Kobir, \& Y. L. Cao (Eds.), Knowledge Management Strategies and Applications (p. 252). IntechOpen Limited. https://doi.org/10.5772/intechopen.70351

Hooper, D., Coughlan, J., \& Mullen, M. R. (2008). Structural Equation Modelling: Guidelines for Determining Model Fit. The Electronic Journal of Business Research Methods, 6, 53-60.

Hornbæk, K., \& Hertzum, M. (2017). Technology Acceptance and User Experience: A Review of the Experiential Component in HCI. ACM Transactions on Computer-Human Interaction, 24, Article No. 33. https://doi.org/10.1145/3127358

Howitt, D., \& Cramer, D. (2020). Research Methods in Psychology(6th ed.). Pearson

Hu, L.-T., \& Bentler, P. M. (1999). Cutoff Criteria for Fit Indexes in Covariance Structure Analysis: Conventional Criteria versus New Alternatives. Structural Equation Modeling, 6, 1-55. https://doi.org/10.1080/10705519909540118

Hubert, M., Blut, M., Brock, C., Zhang, R. W., Koch, V., \& Riedl, R. (2018). The Influence of Acceptance and Adoption Drivers on Smart Home Usage. European Journal of Marketing, 53, 1073-1098. https://doi.org/10.1108/EJM-12-2016-0794

Iacovou, C. L. et al. (1995). Electronic Data Interchange and Small Organizations: Adoption and Impact of Technology. MIS Quarterly, 19, 465-485.

https://doi.org/10.2307/249629

Infosys Limited (2018). Infosys to Announce First Quarter Results on July 13, 2018. Infosys.

John, P., \& Benet-Martinez, V. (2000). Measurement: Reliability, Construct Validation, and Scale Construction. In H. T. Reis, \& C. M. Judd (Eds.), Handbook of Research Methods in Social and Personality Psychology (pp. 339-370). Cambridge University Press.

Joo, S. H., \& Kim, Y. (2017). Measuring Relatedness between Technological Fields. Scientometrics, 83, 435-454. https://doi.org/10.1007/s11192-009-0108-9

Junco, R., \& Cotten, S. R. (2012). The Relationship between Multitasking and Academic Performance. Computers and Education, 59, 505-514. 
https://doi.org/10.1016/j.compedu.2011.12.023

Jung, T., \& Ejermo, O. (2014). Demographic Patterns and Trends in Patenting: Gender, Age, and Education of Inventors. Technological Forecasting and Social Change, 86, 110-124. https://doi.org/10.1016/j.techfore.2013.08.023

Kabir, S. M. (2016). Measurement Concepts: Variable, Reliability, Validity, and Norm. Basic Guidelines for Research: An Introductory Approach for All Disciplines, 72-110.

Karakaya-Ozyer, K., \& Aksu-Dunya, B. (2018). A Review of Structural Equation Modeling Applications in Turkish Educational Science Literature, 2010-2015. International Journal of Research in Education and Science (IJRES), 4, 279-291. https://doi.org/10.21890/ijres.383177

Karimi, J., \& Walter, Z. (2015). The Role of Dynamic Capabilities in Responding to Digital Disruption: A Factor-Based Study of the Newspaper Industry. Journal of Management Information Systems, 32, 39-81. https://doi.org/10.1080/07421222.2015.1029380

Karki, T., Keinänen, H., Tuominen, A., Hoikkala, M., Matikainen, E., \& Maijala, H. (2018). Meaningful Learning with Mobile Devices: Pre-Service Class Teachers Experiences of Mobile Learning in the Outdoors. Technology, Pedagogy and Education, 27, 251-263. https://doi.org/10.1080/1475939X.2018.1430061

Ke, C.-H., Sun, H.-M., Jung, C., \& Yang, Y.-C. (2012). Effects of User and System Characteristics on Perceived Usefulness and Perceived Ease of Use for the Web-Based Classroom Response System. Turkish Online Journal of Educational Technology, 11, 128-143.

Kim, C., Mirusmonov, M., \& Lee, I. (2010). An Empirical Examination of Factors Influencing the Intention to Use Mobile Payment. Computers in Human Behavior, 26, 310-322. https://doi.org/10.1016/j.chb.2009.10.013

Kim, J., \& Forsythe, S. (2010). Factors Affecting Adoption of Product Virtualization Technology for Online Consumer Electronics Shopping. International Journal of Retail and Distribution Management, 38, 190-204. https://doi.org/10.1108/09590551011027122

King, A., \& Baatartogtokh, B. (2015). Research Feature How Useful Is the Theory of Disruptive Innovation. MIT Sloan Management Review, 57, 77-90.

Kirschner, P. A., \& Karpinski, A. C. (2010). Facebook ${ }^{\circ}$ and academic performance. Computers in Human Behavior, 26, 1237-1245. https://doi.org/10.1016/j.chb.2010.03.024

Kivunja, C., \& Kuyini, A. B. (2017). Understanding and Applying Research Paradigms in Educational Contexts. International Journal of Higher Education, 6, 26-41. https://doi.org/10.5430/ijhe.v6n5p26

Klang, M. (2006). Disruptive Technology, Effects of Technology Regulation on Democ$\operatorname{racy}(\mathrm{p} .234)$.

Kline, R. B. (2005). Principles and Practice of Structural Equation Modeling (2nd ed.). Guilford Press.

Koenig-Lewis, N., \& Palmer, A. (2014). The Effects of Anticipatory Emotions on Service Satisfaction and Behavioural Intention. Journal of Services Marketing, 28, 437-451. https://doi.org/10.1108/JSM-09-2013-0244

Krouskos, S., Hood, J. \& Casey, W. (2018). The Stress Tests Every Business Need: A Capital Agenda for Confidently Facing Digital Disruption, Difficult Investors, Recessions and Geopolitical Threats. Wiley.

Kuhn, T. S. (1962). Internet Encyclopedia of Philosophy. A Peer Review of Academic Resource.

Kujala, S., Mugge, R., \& Miron-Shatz, T. (2017). The Role of Expectations in Service 
Evaluation: A Longitudinal Study of a Proximity Mobile Payment Service. International Journal of Human Computer Studies, 98, 51-61. https://doi.org/10.1016/j.ijhcs.2016.09.011

Kyriazos, T. A. (2018). Applied Psychometrics: The Application of CFA to MultitraitMultimethod Matrices (CFA-MTMM). Psychology, 9, 2625-2648. https://doi.org/10.4236/psych.2018.912150

Lance, C. E., \& Vandenberg, R. J. (2002). Confirmatory Factor Analysis. In F. Drasgow, \& N. Schmitt (Eds.), Measuring and Analysing Behaviour in Organizations: Advances in Measurement and Data Analysis (pp. 221-254). Jossey-Bass.

Lather, P. (1986). Issues of Validity in Openly Ideological Research: Between a Rock and a Soft Place. Interchange, 17, 63-84. https://doi.org/10.1007/BF01807017

Lavrakas, P. (2008). Encyclopedia of Survey Research Methods. Encyclopedia of Survey Research Methods.

Lee, S., \& Chung, J. (2009). User Acceptance of a Digital Library System in Developing Countries: An Application of the Technology Acceptance Model. International Journal of Information Management, 29, 196-209. https://doi.org/10.1016/j.ijinfomgt.2008.07.001

Leedy, D. (1997). Practical Research: Planning and Design. Prentice-Hall.

Legner, C., Eymann, T., Hess, T., Matt, C., Böhmann, T., Drews, P., Mädche, A., Urbach, N., \& Ahlemann, F. (2017). Digitalization: Opportunity and Challenge for the Business and Information Systems Engineering Community. Business \& Information Systems Engineering, 59, 301-308. https://doi.org/10.1007/s12599-017-0484-2

Leonidou, L. C., Fotiadis, T. A., Christodoulides, P., Spyropoulou, S., \& Katsikeas, C. S. (2015). Environmentally Friendly Export Business Strategy: Its Determinants and Effects on Competitive Advantage and Performance. International Business Review, 24, 798-811. https://doi.org/10.1016/j.ibusrev.2015.02.001

Levario, T. J., Zhao, C., Rouse, T., Shvartsman, S. Y., \& Hang, L. (2016). An Integrated Platform for Large-Scale Data Collection and Precise Perturbation of Live Drosophila Embryos. Scientific Reports.

Li, C. (2016). The Top Digital Transformation Priorities. The European Business Reviews.

Li, Z., Yang, C., Huang, Q., Liu, K., \& Hu, F. (2017). Big Data and Cloud Computing: Innovation Opportunities and Challenges. International Journal of Digital Earth, 10, 13-53. https://doi.org/10.1080/17538947.2016.1239771

Liao, C., Chen, J. L., \& Yen, D. C. (2007). Theory of Planning Behaviors (TPB) and Customer Satisfaction in the Continued Use of E-Service: An Integrated Model. Computers in Human Behavior, 23, 2804-2822. https://doi.org/10.1016/j.chb.2006.05.006

Lin, H. F., \& Lin, S. M. (2008). Determinants of E-Business Diffusion: A Test of the Technology Diffusion Perspective. Technovation, 28, 135-145.

https://doi.org/10.1016/j.technovation.2007.10.003

Lippert, S. K., \& Govindarajulu, C. (2006). Technological, Organizational, and Environmental Antecedents to Web Services Adoption. Communications of the IIMA, 6 , 146-158.

Ly, A., Verhagen, J., \& Wagenmakers, E. J. (2015). Harold Jeffreys's Default Bayes Factor Hypothesis Tests: Explanation, Extension, and Application in Psychology. Journal of Mathematical Psychology, 72, 19-32. https://doi.org/10.1016/j.jmp.2015.06.004

MacCallum, R. C., \& Austin, J. T. (2000). Applications of Structural Equation Modeling in Psychological Research. Annual Review of Psychology, 51, 201-226. 
https://doi.org/10.1146/annurev.psych.51.1.201

Madary, M., \& Metzinger, T. K. (2016). Real Virtuality: A Code of Ethical Conduct. Recommendations for Good Scientific Practice and the Consumers of VR-Technology. Frontiers in Robotics and AI, 3, 3. https://doi.org/10.3389/frobt.2016.00003

Maiti, S. S., \& Mukherjee, B. N. (1991). Two New Goodness-of-Fit Indices for Covariance Matrices with Linear Structures. British Journal of Mathematical and Statistical Psychology, 44, 153-180. https://doi.org/10.1111/j.2044-8317.1991.tb00953.x

Malaeb, Z. A., Summers, J. K., \& Pugesek, B. H. (2000). Using Structural Equation Modeling to Investigate Relationships among Ecological Variables. Environmental and Ecological Statistics, 7, 93-111. https://doi.org/10.1023/A:1009662930292

Maricar, A. (2014). Determinant Factors of Disruptive Technology_Case Study of WebBased Airplane Ticket Selling. Procedia-Social and Behavioural Sciences, 115, 424-429. https://doi.org/10.1016/j.sbspro.2014.02.449

Massey, A., \& Miller, S. J. (2019). Tests of Hypotheses Using Statistics. Mathematics Department Brown University Providence. Annual Review of Criminology, 4, 209-223.

McArthur, J. W., \& Sachs, J. D. (2002). The Growing Competitiveness Index: Measuring Technological Advancement and the Stages of Development. Center for International Development at Harvard University.

McFarland, D., \& Hamilton, D. (2006). Adding Contextual Specificity to the Technology Acceptance Model. Computers in Human Behaviour, 22, 427-447. https://doi.org/10.1016/j.chb.2004.09.009

McQuivey, J. (2014). Digital Disruption: Unleashing the Next Wave of Innovation. Forrester Research, Publication.

Meena, R., \& Ganesan, P. (2019). Impact of Digital Disruption on Human Capital of Banking Sector. The International Journal of Analytical and Experimental Modal Analysis.

Melville, N., Kraemer, K., \& Gurbaxani, V. (2004). Review: Information Technology and Organizational Performance: An Integrative Model of Its Business Value. MIS Quarterly: Management Information Systems, 28, 283-322. https://doi.org/10.2307/25148636

Menon, A., Bharadwaj, S., Adidam, P. T., \& Edison, S. (1999). Antecedents and Consequences of Marketing Strategy Making. The Journal of Marketing, 63, 18-40. https://doi.org/10.1177/002224299906300202

Mesthene, E. (1970). Technological Change: Its Impact on Man and Society(127 p). Harvard University Press.

Moon, J., \& Kim (2001). Extending the TAM for a World-Wide-Web Context. Information \& Management, 38, 217-230. https://doi.org/10.1016/S0378-7206(00)00061-6

Mouakket, S. (2009). The Effect of Exogenous Factors on the Technology Acceptance Model for Online Shopping in the UAE. Article in International Journal of Electronic Business, 7, 491-511. https://doi.org/10.1504/IJEB.2009.028153

Nysveen, H., Pedersen, P. E., \& Thorbjornsen, H. (2005a). Explaining Intention to Use Mobile Chat Services: Moderating Effects of Gender. Journal of Consumer Marketing, 22, 247-256. https://doi.org/10.1108/07363760510611671

Nysveen, H., Pedersen, P. E., \& Thorbjørnsen, H. (2005b). Intentions to Use Mobile Services: Antecedents and Cross-Service Comparisons. Journal of the Academy of Marketing Science, 33, 330-346. https://doi.org/10.1177/0092070305276149

Oghuma, A. P., Libaque-Saenz, C. F., Wong, S. F., \& Chang, Y. (2016). An Expectation- 
Confirmation Model of Continuance Intention to Use Mobile Instant Messaging. Telematics and Informatics, 33, 34-47. https://doi.org/10.1016/j.tele.2015.05.006

Oliveira, T., Thomas, M., Baptista, G., \& Campos, F. (2016). Mobile Payment: Understanding the Determinants of Customer Adoption and Intention to Recommend the Technology. Computers in Human Behaviour, 61, 401-414. https://doi.org/10.1016/j.chb.2016.03.030

Orlikowski, W. J. (2000). Using Technology and Constituting Structures: A Practice Lens for Studying Technology in Organizations. Organization Science, 11, 404-428. https://doi.org/10.1287/orsc.11.4.404.14600

Orsatti, J., \& Riemer, K. (2015). Identity-Making: A Multimodal Approach for Researching Identity in Social Media. ECIS 2015 Completed Research Papers, Paper 140.

Ozkok, O., Zyphur, M. J., Barsky, A. P., Theilacker, M., Donnellan, M. B., \& Oswald, F. L. (2019). Modeling Measurement as a Sequential Process: Autoregressive Confirmatory Factor Analysis (AR-CFA). Frontiers in Psychology, 10, 2108. https://doi.org/10.3389/fpsyg.2019.02108

Palekar, S., \& Sedera, D. (2012). The Competing-Complementarity Engagement of News Media with Online Social Media. Proceedings of the 16th Pacific Asia Conference on Information Systems, Paper 164.

Parida, V., Sjödin, D., \& Reim, W. (2019). Reviewing Literature on Digitalization, Business Model Innovation, and Sustainable Industry: Past Achievements and Future Promises. Sustainability (Switzerland), 11, 391. https://doi.org/10.3390/su11020391

Park, Y. (2012). University Students' Behavioral Intention to Use Mobile Learning: Evaluating the Technology Acceptance Model. Journal of Computing in Higher Education, 27, 94-113. https://doi.org/10.1111/j.1467-8535.2011.01229.x

Pena-García, N., Gil-Saura, I., Rodríguez-Orejuela, A., \& Siqueira-Junior, J. R. (2020). Purchase Intention and Purchase Behavior Online: A Cross-Cultural Approach. $\mathrm{He}$ liyon, 6, e04284. https://doi.org/10.1016/j.heliyon.2020.e04284

Perdana, S. (2019) Perpustakaan Negara Malaysia Cataloguing-in-Publication Data Malaysia Digital Economy Blueprint.

Peteraf, M., Di Stefano, G., \& Verona, G. (2013). The Elephant in the Room of Dynamic Capabilities: Bringing Two Diverging Conversations Together. Strategic Management Journal, 34, 1389-1410. https://doi.org/10.1002/smj.2078

Pew Research Center (2017). Experts on the Future of Work, Jobs Training and Skills. Pew Research Center.

Pfeffer, J., \& Leblebici, H. (1977). Information Technology and Organizational Structure. Pacific Sociological Review, 20, 241-261. https://doi.org/10.2307/1388934

Porter, E. (1998). Clusters and Competition: New Agendas for Companies, Governments, and Institutions. In M. Porter (Ed.), On Competition (pp. 197-287). Harvard Business School Press.

Porter, M. E., \& Millar, V. E. (1985). How Information Gives You Competitive Advantage. Harvard Business School.

Porter, M. (1995). The Competitive Advantage of the Inner City. Harvard Business Review, 73, 55-71.

Premkumar, G., \& Roberts, M. (1999). Adoption of New Information Technologies in Rural Small Businesses. Omega, 27, 467-484.

https://doi.org/10.1016/S0305-0483(98)00071-1

Priyanka, K., \& Kumar, A. (2013). Understanding the Evolution of Technology Accep- 
tance Model. International Journal of Advanced Research in Computer Science and Management Studies, 6, 144-148.

Productivity Commission (2016). How to Assess the Competitiveness and Efficiency of the Superannuation System. Productivity Commission Research Report.

PwC (2017). How Does a Retailer Manage the Digital Disruption to Win Customers? Industry Insights, PWC UK Blogs.

Rachinger, M., Rauter, R., Müller, C., Vorraber, W., \& Schirgi, E. (2019). Digitalization and Its Influence on Business Model Innovation. Journal of Manufacturing Technology Management, 30, 1143-1160. https://doi.org/10.1108/JMTM-01-2018-0020

Radner, R., \& Rothschild, M. (2005). On the Allocation of Effort. Journal of Economic Theory, 10, 358-376. https://doi.org/10.1016/0022-0531(75)90006-X

Rahi, S. (2017). Research Design and Methods: A Systematic Review of Research Paradigms, Sampling Issues and Instruments Development. International Journal of Economics \& Management Sciences, 6, Article ID: 1000403.

Ramdani, B., Kawalek, P., \& Lorenzo, O. (2009). Predicting SMEs' Adoption of Enterprise Systems. Journal of Enterprise Information Management, 22, 10-24. https://doi.org/10.1108/17410390910922796

Rauch, M., Wenzel, M., \& Wagner, H.-T. (2016). The Digital Disruption of Strategic Paths: An Experimental Study. Proceedings of the 37th International Conference on Information Systems, Dublin, 2016, 1-19.

Ray, G., Xue, L., \& Barney, J. B. (2012). Impact of Information Technology Capital on Firm Scope and Performance: The Role of Asset Characteristics. Academy of Management Journal, 56, 1125-1147. https://doi.org/10.5465/amj.2010.0874

Redbord, M. (2020). 14 Ways Technology Will Affect the Future of Customer Service.

Reddy, N. M., \& Zhao, L. (1990). International Technology Transfer: A Review. Research Policy, 19, 285-307. https://doi.org/10.1016/0048-7333(90)90015-X

Reich, H., \& Benbasat, I. (1990). An Empirical Investigation of Factors Influencing the Success of Customer-Oriented Strategic Systems. Information Systems Research, 1, 325-347. https://doi.org/10.1287/isre.1.3.325

Revels, J., Tojib, D., \& Tsarenko, Y. (2010). Understanding Consumer Intention to Use Mobile Services. Australasian Marketing Journal, 18, 74-80. https://doi.org/10.1016/j.ausmj.2010.02.002

Rogers, E. M. (1962). Diffusion of Innovations (3rd Edition). The Free Press of Glencoe Division of The Macmillan Co.

Rogers, E. M. (1983). Diffusion of Innovations. New York: The Free Press.

Roscoe, T. (1975). Fundamentals Research Statistics for Behavioral Sciences. In R. Hill (1998), What Sample Size Is Enough in Internet Survey Research?

Rossi, B. (2017). Digital Disruption Will Wipe out $40 \%$ of Fortune 500 Firms in the Next 10 Years, Say C-Suite Execs. Information Age.

Safeena, R., Date, H., Hundewale, N., \& Kammani, A. (2013). Combination of TAM and TPB in Internet Banking Adoption. International Journal of Computer Theory and Engineering, 5, 146-150. https://doi.org/10.7763/IJCTE.2013.V5.665

Salesforce Research (2020). What Are Customer Expectations, and How Have They Changed? Salesforce.com.

Sapsford, R., \& Jupp, V. (2012). Data Collection and Analysis. African Journal of Business Management, 5. 
Saunders, M., Lewis, P., \& Thornhill, A. (2012). Research Methods for Business Students (6th ed.). Pearson Education.

Saunders, M., Lewis, P., \& Thornhill, A. (2016). Research Methods for Business Students (7th ed.). Pearson.

Schwab, K. (2016). The Fourth Industrial Revolution: What It Means and How to Respond. World Economic Forum.

Sekaran, U., \& Bougie, R. (2013). Research Methods for Business: A Skill Building Approach (6th Ed.). John Wiley \& Sons Ltd.

Shaw, R. L., Hiles, D. R., West, K., Holland, C., \& Gwyther, H. (2018). From Mixing Methods to the Logic(s) of Inquiry: Taking a Fresh Look a Developing Mixed Design Studies. Health Psychology and Behavioral Medicine, 6, 226-244. https://doi.org/10.1080/21642850.2018.1515016

Shim, S. (2019). Digital Transformation-An Essential Disruption. Digital, Digital Transformation, Technology.

Shoter, A. M., Bataineh, A. Q., \& Arabia, S. (2016). Building a Model for Determining the Factors Affecting Mobile Marketing Acceptance and Adoption. International Review of Management and Business Research, 5, 986-1007.

Showkat, N., \& Parveen, H. (2017). Non-Probability and Probability Sampling. e-PG Pathshala.

Siddaway, A. P., Wood, A. M., \& Taylor, P. J. (2017). The Center for Epidemiologic Studies-Depression (CES-D) Scale Measures a Continuum from Well-Being to Depression: Testing Two Key Predictions of Positive Clinical Psychology. Journal of Affective Disorders, 213, 180-186. https://doi.org/10.1016/j.jad.2017.02.015

Sifers, S. K., Puddy, R. W., Warren, J. S., \& Roberts, M. C. (2002). Reporting of Demographics, Methodology, and Ethical Procedures in Journals in Pediatric and Child Psychology. Journal of Pediatric Psychology, 27, 19-25.

https://doi.org/10.1093/jpepsy/27.1.19

Sileyew, J. K. (2020). Research Design and Methodology. Semantic Scholar, Cyberspace. https://doi.org/10.5772/intechopen.85731

Skog, D. A., Wimelius, H., \& Sandberg, J. (2018). Digital Disruption. Business \& Information Systems Engineering, 60, 431-437. https://doi.org/10.1007/s12599-018-0550-4

Snowden, S., Spafford, J., Michaelides, R., \& Hopkins, J. (2006). Technology Acceptance and $\mathrm{m}$-Commerce in an Operational Environment. Journal of Enterprise Information Management, 19, 525-539. https://doi.org/10.1108/17410390610703657

Soewarno, N., Tjahjadi, B., \& Permatanadia, D. (2020). Competitive Pressure and Business Performance in East Java Batik Industry. The Journal of Asian Finance, Economics and Business, 7, 326-336. https://doi.org/10.13106/jafeb.2020.vol7.no12.329

Sommer, R., \& Sommer, B. (2001). Practical Guide to Behavioral Research; Tools and Techniques. Oxford University Press.

Spreng, R. A., \& Page, T. J. (2001). The Impact of Confidence in Expectations on Consumer Satisfaction. Psychology and Marketing, 18, 1187-1204.

https://doi.org/10.1002/mar.1049

Stage, F. K., Carter, H. C., \& Nora, A. (2004). Path Analysis: An Introduction and Analysis of a Decade of Research. Journal of Educational Research, 98, 5-13. https://doi.org/10.3200/JOER.98.1.5-13

Stein, C. M., Morris, N. J., \& Nock, N. L. (2012). Structural Equation Modeling. Methods in Molecular Biology, 850, 495-512. https://doi.org/10.1007/978-1-61779-555-8 27 
Stewart, B., Schatz, R., \& Khare, A. (2016). Making Sense of Digital Disruption Using a Conceptual Two-Order Model. In A. Khare, B. Stewart, \& R. Schatz (Eds.), Phantom EX Machina (pp. 3-21). Springer. https://doi.org/10.1007/978-3-319-44468-0 1

Sun, A. Y., \& Scanlon, B. R. (2019). How Can Big Data and Machine Learning Environment and Water Management: A Survey of Methods, Applications, and Future Directions. Environmental Research Letters, 14, Article ID: 073001. https://doi.org/10.1088/1748-9326/ab1b7d

Taber, S. K. (2017). The Use of Cronbach's Alpha When Developing and Reporting Research Instruments in Science Education. Research in Science Education, 48, 1273-1296. https://doi.org/10.1007/s11165-016-9602-2

Taherdoost, H. (2016). Sampling Methods in Research Methodology; How to Choose a Sampling Technique for Research. SSRN Electronic Journal, 5, 18-27.

https://doi.org/10.2139/ssrn.3205035

Taherdoost, H. (2019). What Is the Best Response Scale for Survey and Questionnaire Design; Review of Different Lengths of Rating Scale, Attitude Scale, Likert Scale. International Journal of Academic Research in Management.

Tan, F. T. C., Tan, B., \& Pan, S. L. (2016). Developing a Leading Digital Multi-Sided Platform: Examining IT Affordances and Competitive Actions. Communications of the Association for Information Systems, 38, 738-760. https://doi.org/10.17705/1CAIS.03836

Tech Wire Asia (2018). Which Technologies Are Helping Companies Transform the Travel Industry?

Tenner, E. (2019). Unlocking the Creative Value of Inefficiency.

Teo, B.-C., Mustaffa, M. A., \& Rozi, A. I. M. (2018). To Grab or Not to Grab? Passenger Ride Intention towards E-Hailing Services. Malaysian Journal of Consumer and Family Economics, 21, 153-159.

Teo, T. (2013). Initial Development and Validation of a Digital Natives Assessment Scale (DNAS) in Computers \& Education. Computers \& Education, 67, 51-57.

https://doi.org/10.1016/j.compedu.2013.02.012

The World Forum (2017). How Are Today's Biggest Tech Trends Affecting Our Human Rights? World Forum Report.

TheStar (2019). Digital Disruption to Drive Revenue Growth in 2019. Thestar.com.my/ business.

Thomas, D. R. (2016). A General Inductive Approach for Analyzing Qualitative Evaluation Data. American Journal of Evaluation, 27, 237-246. https://doi.org/10.1177/1098214005283748

Thong, J. (1999). An Integrated Model of Information System Adaption in Small Businesses. Journal of Management Information Systems, 15, 187-214. https://doi.org/10.1080/07421222.1999.11518227

Thong, J. Y. L., Hong, S. J., \& Tam, K. Y. (2006). The Effects of Post-Adoption Beliefs on the Expectation-Confirmation Model for Information Technology Continuance. International Journal of Human Computer Studies, 64, 799-810. https://doi.org/10.1016/j.ijhcs.2006.05.001

Tidd, J., \& Bessant, J. (2018). Managing Innovation Integrating Technological, Market and Organizational Change (6th ed.). Wiley.

Toolan, T. (2017). Competing in a Global Market-What's Your Competitive Advantage?

Tornjanski, V., Knezevic, S., \& Delibasic, B. (2017). A CRM Performance Measurement 
in Banking Using Integrated BSC and Customized ANP-BOCR Approach. Management: Journal of Sustainable Business and Management Solutions in Emerging Economies, 22, 71-85. https://doi.org/10.7595/management.fon.2017.0004

Trochim, M., \& Donnelly, J. (2006). Research Methods: The Essential Knowledge Base. Cengage Learning.

Turner, S., \& Endres, A. (2017). Strategies for Enhancing Small-Business Owners' Success Rates. International Journal of Applied Management and Technology, 16, 34-49. https://doi.org/10.5590/IJAMT.2017.16.1.03

Tzini, K., \& Jain, K. (2018). Unethical Behaviour under Relative Performance Evaluation: Evidence and Remedy. Human Resource Management, 57, 1399-1413.

https://doi.org/10.1002/hrm.21913

Unctad (2018). Technology and Innovation Report 2018: Harnessing Frontier Technologies for Sustainable Development.

Ursachi, G., Horodnic, I. A., \& Zait, A. (2015). How Reliable Are Measurement Scales? External Factors with Indirect Influence on Reliability Estimators. Procedia Economics and Finance, 20, 679-686. https://doi.org/10.1016/S2212-5671(15)00123-9

Vagnani, G., \& Volpe, L. (2017). Innovation Attributes and Managers' Decisions about the Adoption of Innovations in Organizations: A Meta-Analytical Review. International Journal of Innovation Studies, 1, 107-133. https://doi.org/10.1016/j.ijis.2017.10.001

Valverde, S. (2016). Major Transitions in Information Technology. Philosophical Transactions of the Royal Society B: Biological Sciences, 331, Article ID: 20150450. https://doi.org/10.1098/rstb.2015.0450

Van Belleghem, S. (2015). When Digital Becomes Human: The Transformation of Customer Relationships. Kogan Page.

Vanhaverbeke, W., Roijakkers, N., Lorenz, A., \& Chesbrough, H. (2017.) The Importance of Connecting Open Innovation to Strategy. Strategy and Communication for Innovation: Integrative Perspectives on Innovation in the Digital Economy, 3.

Venkatesh, V., \& Davis, F. D. (2000). A Theoretical Extension of the Technology Acceptance Model; Four longitudinal Field Studies. Management Science, 46, 186-204. https://doi.org/10.1287/mnsc.46.2.186.11926

Verhoef, P. C., Broekhuizen, T., Bart, Y., Bhattacharya, A., Dong, J.Q., Fabian, N., \& Haenlein, M. (2019). Digital Transformation: A Multidisciplinary Reflection and Research Agenda. Journal of Business Research, 122, 889-901.

https://doi.org/10.1016/j.jbusres.2019.09.022

Vijay, M., \& Sharma, K. (2020). Methods of Data Collection-Observation, Interview \& Focus Group Discussion. Department of Social Work.

Vijayasarathy, L. R. (2004). Predicting Consumer Intentions to Use On-Line Shopping: The Case for an Augmented Technology Acceptance Model. Information and Management, 41, 747-762. https://doi.org/10.1016/j.im.2003.08.011

Vogels, E., Rainie, L., \& Anderson, J. (2020). Tech Causes More Problems than It Solves. Pew Research Center.

Von Briel, F., Davidsson, P., \& Recker, J. (2018). Digital Technologies as External Enablers of New Venture Creation in the IT Hardware Sector. Entrepreneurship Theory and Practice, 42, 47-69. https://doi.org/10.1177/1042258717732779

Wahab, S. A., Rose, R. C., Osman, S. I. W. (2012). Defining the Concepts of Technology and Technology Transfer: A Literature Analysis. International Business Research, 5, 61-71. 
Wang, X., French, B. F., \& Clay, P. F. (2015). Convergent and Discriminant Validity with Formative Measurement: A Mediator Perspective. Journal of Modern Applied Statistical Methods, 14, Article 11. https://doi.org/10.22237/jmasm/1430453400

Wei, T. T. et al. (2009). What Drives Malaysian m-Commerce Adoption? An Empirical Analysis. Industrial Management \& Data Systems, 109, 370-388. https://doi.org/10.1108/02635570910939399

Weinreich, N. (2009). Integrating Quantitative and Qualitative Methods in Social Marketing Research. Social Marketing Quarterly, 3, 53-58. https://doi.org/10.1177/152450049600300106

Westfall, H. (2014). Kurtosis as Peakedness. The American Statistician, 68, 191-195. https://doi.org/10.1080/00031305.2014.917055

Westerman, \& Bonnet (2015). Revamping Your Business through Digital Transformation. 56.

Wheaton, B., Muthen, B., Alwin, D. F., \& Summers, G. F. (1977). Assessing Reliability and Stability in Panel Models. Sociological Methodology, 8, 84-136. https://doi.org/10.2307/270754

World Bank (2018). Malaysia's Digital Economy: A New Driver of Development. World Bank Group, Global Knowledge and Research Hub.

World Economic Forum (2017). Technology and Innovation for the Future of Production: Accelerating Value Creation. White Paper, World Economic Forum.

World Robotics Report (2016). International Federation of Robotics. IFR, International Federation of Robotics.

Wortmann, F., \& Flüchter, K. (2015). Internet of Things-Technology and Value Added. Business \& Information Systems Engineering, 57, 221-224. https://doi.org/10.1007/s12599-015-0383-3

Yang, S. G. (2010). Competitive Strategy and Business Environment: The Case of Small Enterprises in China. Asian Social Science, 6, 64-71. https://doi.org/10.5539/ass.v6n11p64

Zainudin, A. (2012). Research Methodology for Business and Social Science (16 p). Universiti Teknologi MARA Publication Centre (UPENA).

Zhang, J., \& Mao, E. (2008). Understanding the Acceptance of Mobile SMS Advertising among Young Chinese Consumers. Psychology and Marketing, 25, 787-805. https://doi.org/10.1002/mar.20239

Zhu, K., Kraemer, K. L., \& Xu, S. (2006). The Process of Innovation Assimilation by Firms in Different Countries: A Technology Diffusion Perspective on E-Business. Management Science, 52, 1557-1576. https://doi.org/10.1287/mnsc.1050.0487

Zohrabi, M. (2013). Mixed Method Research: Instruments, Validity, Reliability and Reporting Findings. Theory and Practice in Language Studies, 3, 254-262. https://doi.org/10.4304/tpls.3.2.254-262

Zolkefli, Y. (2020). Ethical Leadership in Nursing during the Covid-19 Pandemic. The Malaysian Journal of Nursing (MJN), 12, 3-4. https://doi.org/10.31674/mjn.2020.v12i02.001 